FEDERAL RESERVE BANK OF SAN FRANCISCO

WORKING PAPER SERIES

\title{
The Relative Price and Relative Productivity Channels for Aggregate Fluctuations
}

\author{
Eric T. Swanson \\ Federal Reserve Bank of San Francisco
}

June 2006

Working Paper 2006-20

http://www.frbsf.org/publications/economics/papers/2006/wp06-20bk.pdf

The views in this paper are solely the responsibility of the authors and should not be interpreted as reflecting the views of the Federal Reserve Bank of San Francisco or the Board of Governors of the Federal Reserve System. 


\title{
The Relative Price and Relative Productivity Channels for Aggregate Fluctuations
}

\author{
Eric T. Swanson \\ Federal Reserve Bank of San Francisco \\ eric.swanson@sf.frb.org
}

\begin{abstract}
This paper demonstrates that sectoral heterogeneity itself-without any additional bells or whistles - has first-order implications for the transmission of aggregate shocks to aggregate variables in an otherwise standard DSGE model. The effects of sectoral heterogeneity on this transmission are decomposed into two channels: a "relative price" channel and a "relative productivity" channel. The relative price channel results from changes in the relative prices of aggregates, such as investment vis-a-vis consumption goods, which occurs in a sectoral model in response to even standard aggregate shocks. The relative productivity channel arises from changes in the distribution of inputs across sectors. We show that, for standard sectoral models, this latter channel is second-order, but becomes first-order if we consider a nontraded input such as capital utilization or introduce a wedge that thwarts the steady-state equalization of marginal products of a traded input across sectors. For reasonable parameterizations, the relative productivity channel causes aggregate productivity to vary procyclically in response to non-technological shocks such as changes in government purchases.
\end{abstract}

JEL Classification: E32, E37, O47

Version 3.1

June 30, 2006

I thank Michael Horvath, Robert Hall, John Taylor, Pierre-Olivier Gourinchas, John Fernald, Richard Rogerson, an anonymous referee, the editor, and seminar participants at the Federal Reserve Board, the Federal Reserve Bank of Kansas City, the University of Maryland, and the Society for Economic Dynamics Meetings for helpful discussions, comments, and suggestions. The views expressed in this paper, and all errors and omissions, should be regarded as those solely of the author, and are not necessarily those of the individuals listed above, the management of the Federal Reserve Bank of San Francisco, the Board of Governors of the Federal Reserve, or any other individual in the Federal Reserve System. 


\section{Introduction}

Heterogeneity in the economy is ubiquitous: people have different tastes, are employed in different industries, and consume goods that are different from those that are used for investment. This paper demonstrates that the existence of heterogeneous sectors of an economy alters in important ways the responses of macroeconomic variables to macroeconomic shocks in an otherwise standard dynamic stochastic general equilibrium (DSGE) framework.

Previous authors investigating sectoral heterogeneity (e.g., Rogerson, 1987, Ramey and Shapiro, 1998) have focused on the implications of adjustment costs to moving resources across sectors. In their models, a worker can only move from sector $A$ to sector $B$ of the economy if society pays a "retraining cost" of $x$ dollars (Ramey and Shapiro consider adjustment costs to capital mobility rather than labor mobility, but the modeling and the effects are very similar). They show that these costs, and the frictions on resource mobility they imply, can significantly exacerbate an economic downturn.

In this paper, we abstract away from adjustment costs in order to demonstrate how sectoral heterogeneity - in and of itself - has implications for the response of aggregate variables to aggregate shocks in the standard DSGE framework. In particular, capital is a predetermined or state variable in standard DSGE models, so capital cannot respond within the period to an economic shock. In a mutliple-sector DSGE model, this assumption alone is sufficient for heterogeneous sectors of the economy to have first-order implications for the response of macroeconomic variables to even standard macroeconomic shocks - one does not need to assume any adjustment or "retraining" costs.

In a multiple-sector DSGE model, the effects of sectoral heterogeneity on the transmission of aggregate shocks to aggregate variables can be divided into two channels: a "relative price" channel and a "relative productivity" channel. These channels lie on top of the standard effects an aggregate shock would have in a one-sector DSGE setting. The relative price channel arises from the fact that, in a multi-sector model, the relative prices of even aggregate variables such as consumption, investment, and government purchases can and typically will change in response to an aggregate shock. For example, an aggregate technology shock in a DSGE model typically causes investment to rise strongly on impact. As a result, in a multi-sector DSGE model, the relative prices of goods that are 
relatively investment-specific tend to be driven upward, and the aggregate price of a unit of investment in the model rises relative to the price of a unit of consumption and the price of output. This in turn tends to dampen the investment effects of the technology shock and instead channel agents' responses into increased consumption and leisure, relative to a one-sector DSGE model.

The relative productivity channel arises from changes in the distribution of inputs across sectors (as opposed to changes in the aggregate quantities of those inputs, which effects are already captured by the standard one-sector analysis). In many models, this channel has only second-order effects because the marginal product of inputs in different sectors are equalized in steady state. However, when there are inputs that face a distortionary wedge that prevents steady-state marginal products from equalizing, or when there are nontradeable inputs to production such as capital utilization, the effects of the relative productivity channel are first-order. When the marginal product of an input differs across sectors, changes in the sectoral allocation of inputs lead to first-order changes in aggregate output, productivity, consumption, investment, and other aggregate quantities.

The analysis of the relative productivity channel is closely related to the empirical work of Basu and Fernald (1997, 2002). Those authors demonstrate that changes in the sectoral composition of production have important implications for growth accounting, and that failure to account for these effects imparts an upward bias to empirical estimates of aggregate returns to scale and the cyclicality of aggregate productivity. By contrast, the present paper focuses on sectoral heterogeneity as a channel (in fact, two channels) for the amplification and propagation of economic shocks in the DSGE framework. It thus fills a gap in the DSGE literature pointed to by Basu and Fernald.

It should also be emphasized that the results of this paper do not depend on the importance of "reallocative" vs. "aggregate" shocks in the sense of Lilien (1982) and Abraham and Katz (1986). All that is required is some degree of heterogeneity in the economy, so that a given economic shock, whether "reallocative" or "aggregate" in nature, affects different sectors of the economy differently. As mentioned above, even standard macroeconomic shocks, such as changes in government purchases or technology, have this feature in a model with heterogeneous sectors.

The remainder of the paper proceeds as follows. Section two presents baseline oneand $n$-sector DSGE models. Section three demonstrates the existence of the relative price 
channel and provides examples. Section four demonstrates the existence of the relative productivity channel and the need for a wedge between the marginal product of an input across sectors; we argue that variable capital utilization, because it is nontradeable, provides an appealing example of such a wedge. Section five concludes. Two appendices provide details of the numerical solution method used in the examples and a detailed proof of the main proposition in Section 3.

\section{Baseline Models}

\subsection{A Baseline One-Sector Model}

We require a standard one-sector model for use as a benchmark, which we'll refer to as Baseline Model I. A natural choice is the well-known model of King, Plosser, and Rebelo (1988). Although the setup and properties of this model are well understood, it is worth specifying them in some detail to better see the analogies to the multi-sector model in the following section. The basic setup of the model is as follows:

$$
\begin{aligned}
\text { Preferences: } & E_{0} \sum_{t=0}^{\infty} \beta^{t} \frac{C_{t}^{1-\sigma}}{1-\sigma} v\left(1-L_{t}\right) \\
\text { Government: } & \tau Y_{t}=G_{t}+T_{t} \\
\text { Capital Stock: } & K_{t+1}=(1-\delta) K_{t}+\left(Y_{t}-C_{t}-G_{t}\right) \\
\text { Production: } & Y_{t}=F\left(K_{t}, A_{t} L_{t}\right)
\end{aligned}
$$

where $C_{t}$ denotes consumption at time $t, L_{t}$ labor, $K_{t}$ capital, $Y_{t}$ output, $G_{t}$ government purchases, $A_{t}$ technology, $\tau$ the income tax rate, $\delta$ the depreciation rate, $\beta$ the representative agent's discount factor, and $T_{t}$ the lump-sum transfer to consumers (or tax if negative). For simplicity, the population is assumed to be stable and normalized to unity in every period.

Equation (I-1) is the representative agent's objective function, with total labor endowment normalized to unity. The agent's utility kernel is chosen to be consistent with balanced growth, although for simplicity we will abstract away from growth for the remainder of the paper. ${ }^{1}$ Equation (I-2) expresses the government's resource constraint,

\footnotetext{
${ }^{1}$ We interpret the case $\sigma=1$ as the logarithmic utility kernel, $\log C_{t}+v\left(1-L_{t}\right)$, as in King, Plosser, and Rebelo (1987). The function $v$ is required to be twice-differentiable, increasing, and concave, but is otherwise unrestricted.
} 
equation (I-3) describes capital accumulation in the model, and equation (I-4) is the economy's production function, with $F$ unrestricted except for standard regularity conditions (twice-differentiable, increasing, concave, and satisfying gradient Inada-type conditions). Technology $\left\{A_{t}\right\}$ is an exogenous Markov process which, we assume for simplicity, is stationary. Government purchases $\left\{G_{t}\right\}$ are an exogenous stationary Markov process and $\tau$ is constant; thus, lump-sum taxes or transfers $T_{t}$ adjust at the margin to satisfy the government's resource constraint $(\mathrm{I}-3) .^{2}$

The representative agent chooses state-contingent paths for $\left\{L_{t}\right\}$ and $\left\{C_{t}\right\}$ that maximize (I-1) subject to the agent's asset accumulation equation: ${ }^{3}$

$$
\begin{aligned}
K_{t+1} & =\left(1+r_{t}\right) K_{t}+\left((1-\tau) w_{t} L_{t}-C_{t}+T_{t}\right) \\
\text { where } \quad w_{t} & \equiv A_{t} \partial F / \partial(A L) \\
r_{t} & \equiv(1-\tau) \partial F / \partial K-\delta
\end{aligned}
$$

and the transversality condition:

$$
\lim _{t \rightarrow \infty} K_{t+1} / \prod_{s=0}^{t}\left(1+r_{s}\right) \geq 0
$$

taking as given the histories of all relevant variables up to time 0 , the exogenous stochastic processes $\left\{A_{t}\right\}$ and $\left\{G_{t}\right\}$, and the stochastic future path of the vector $\left\{T_{t}, w_{t}, r_{t}\right\}$. An equilibrium of the model is a solution to the agent's problem, above, that takes as given the stochastic, aggregate time paths for $\left\{T_{t}, w_{t}, r_{t}\right\}$ resulting from the agents' consumption and labor supply rules and equations (I-2) through (I-5).

\subsection{The Baseline Multi-Sector Model}

Baseline Model I has a natural generalization to multiple sectors. Let each sector $i=$ $1, \ldots, n$, be characterized by perfect competition, constant returns to scale, and production function $Y_{i t} \equiv F_{i}\left(K_{i t}, A_{i t} L_{i t}\right)$, where $Y_{i t}$ denotes output, $K_{i t}$ capital, and $L_{i t}$ labor input of sector $i$ at time $t, A_{i t}$ is a sector-specific technology parameter, and $F_{i}$ is a sector-specific

\footnotetext{
${ }^{2}$ The simplifying assumptions that are made here are only for convenience and do not alter any of the main points of the paper.

${ }^{3}$ Note that $w_{t}$ and $r_{t}$ effectively stand for both the real and nominal returns to labor and capital, since the price level is normalized to unity in every period.
} 
production function that is twice-differentiable, increasing, concave, and satisfies Inadatype gradient conditions. For simplicity, assume that capital is a homogeneous good, so that there is only one type of capital which serves equally well as an input into each sector $i$ (although different sectors may choose different capital-labor ratios due to differences in production functions $F_{i}$ ). Similarly, assume there is only one type of labor.

Each sector $i$, however, produces a distinct good, with different sectors' goods having potentially different importances in each of consumption, investment, and government purchases. In this paper, we show that this modification to the baseline model alone is sufficient to change in important ways the effects of aggregate shocks on aggregate variables in the model.

Analogous to the baseline one-sector case, capital stocks $K_{i t}$ are state variables of the model. Thus, the $K_{i t}$ are predetermined at the beginning of each period $t$ and remain fixed for the duration of the period. This quasi-fixity of capital is worth emphasizing here because it is crucial for generating changes in relative prices and in relative productivities across sectors after an economic shock.

At time $t$, shocks to the economy are realized, and labor $L_{i t}$ is adjusted by firms in response. In contrast to capital, labor is assumed to be freely mobile both between sectors and in and out of the labor force within the period, as in the baseline one-sector model. Production and consumption at time $t$ take place once the labor adjustment has been made. The characteristic good for each sector $i$ has price $p_{i t}$ at time $t$, determined by supply and demand in that sector.

At the end of each period, investment is executed, and the capital stocks $K_{i t}$ may be adjusted freely, up or down - again, analogous to the baseline one-sector model.

The basic equations of Multi-sector Model II are summarized as follows and are discussed in detail below:

$$
\begin{gathered}
\text { Preferences: } \quad E_{0} \sum_{t=0}^{\infty} \beta^{t} \frac{C_{t}^{1-\sigma}}{1-\sigma} v\left(1-L_{t}\right) \\
\text { where } C_{t} \equiv\left[\sum \eta_{i} C_{i t}^{(\theta-1) / \theta}\right]^{\theta /(\theta-1)} \\
P_{C t} \equiv\left[\sum \eta_{i}^{\theta} p_{i t}^{1-\theta}\right]^{1 /(1-\theta)}
\end{gathered}
$$




$$
\begin{aligned}
\text { Government: } \begin{aligned}
\tau Y_{t} & =P_{G t} G_{t}+T_{t} \\
\text { where } P_{G t} & \equiv \sum \gamma_{i} p_{i t} \\
G_{t} & \equiv \frac{1}{P_{G t}} \sum p_{i t} G_{i t} \\
\text { Capital Stock: } K_{t+1} & =(1-\delta) K_{t}+\frac{1}{P_{K t}}\left(Y_{t}-P_{C t} C_{t}-P_{G t} G_{t}\right) \\
\text { where } P_{K t} & \equiv \sum \xi_{i} p_{i t} \\
\text { Production: } Y_{i t}= & F_{i}\left(K_{i t}, A_{i t} L_{i t}\right) \\
\text { with } K_{t} & \equiv \sum K_{i t} \\
L_{t} & \equiv \sum L_{i t} \\
Y_{t} & \equiv \frac{1}{P_{t}} \sum p_{i t} Y_{i t} \\
P_{t} & \equiv \sqrt{\left(\frac{\sum p_{i t} y_{i 0}}{\sum p_{i 0} y_{i 0}}\right)\left(\frac{\sum p_{i t} y_{i t}}{\sum p_{i 0} y_{i t}}\right)}=1
\end{aligned}
\end{aligned}
$$

Preferences. The equations in (II-1) define the representative agent's preferences as a CES combination of the individual sectoral goods $i$ with weights $\eta_{i}$. We assume a CES functional form for simplicity and also because it provides a theoretically unambiguous measure of real aggregate consumption $C_{t}$ - the definition that is given in (II-1) - which allows us to talk meaningfully about aggregate consumption in the model without having to resort to an ad hoc index (such as a Fisher ideal or Tornqvist index). The corresponding price of a unit of aggregate consumption is also unambiguous and is given by $P_{C t}$, also defined in (II-1). Note that equations (II-1) imply exactly the same set of preferences over aggregate consumption $C_{t}$ as in Baseline Model I, so that Multi-sector Model II is a proper generalization of the standard one-sector model. Also note that not all goods necessarily enter consumers' utility function, so some $\eta_{i}$ may be zero. We normalize the scale of the $\eta_{i}$ so as to set the price of consumption $P_{C t}$ equal to unity in steady state.

Government Purchases. Equations (II-2) describe the government's resource constraint in the multi-sector model. For simplicity, the government's preferences over individual goods $i$ are assumed to be Leontief, with $\gamma_{i}$ units of each good $i$ required to form one unit of government purchases. We assume a Leontief functional form for simplicity and because it provides a theoretically unambiguous definition of real aggregate government 
purchases $G_{t}$, the definition that is given in equations (II-2). Although a CES functional form for $G_{t}$ would also have these advantages and would not change any of the main points of the paper, it would complicate the notation and setup of the model unnecessarily, so we use the simpler Leontief form. The price of a unit of aggregate government purchases is $P_{G t}$, also defined in (II-2). In general, not all goods need be purchased by the government, so some $\gamma_{i}$ may be zero. We normalize the scale of the $\gamma_{i}$ so as to set the price of government purchases $P_{G t}$ equal to unity in steady state.

Analogous to the baseline one-sector model, we assume that government purchases $\left\{G_{i t}\right\}$ in each sector $i$ is an exogenous stationary Markov process and that the tax rate $\tau$ is constant. Thus, lump-sum taxes or transfers $T_{t}$ vary at the margin to satisfy the government's resource constraint in (II-2), as in the one-sector model.

Capital Accumulation. Equations (II-3) describe capital accumulation in the model. Each unit of capital is assumed to be a Leontief combination of the $n$ sectoral goods, with $\xi_{i}$ units of each good $i$ required to form one unit of capital. We assume a Leontief functional form for simplicity and because it provides a theoretically unambiguous definition of real aggregate investment, $I_{t} \equiv K_{t+1}-(1-\delta) K_{t}=\left(Y_{t}-P_{C t} C_{t}-P_{G t} G_{t}\right) / P_{K t}$, as in equations (II-3). ${ }^{4}$ The price of one unit of aggregate investment or capital in the model is given by $P_{K t}$ in (II-3). Not all goods necessarily enter into investment in the model, so that some $\xi_{i}$ may be zero. We normalize the scale of the $\xi_{i}$ so as to set the price of capital $P_{K t}$ equal to unity in steady state.

Production and Aggregate Output. Equations (II-4) describe the economy's multisector production technology. We leave the production functions $F_{i}$ unrestricted except for the usual regularity conditions (twice-differentiable, increasing, concave, and gradient Inada-type boundary conditions). ${ }^{5}$ We normalize the units for output in each sector $i$ so as to set the level of technology $A_{i t}$ in each sector equal to unity in steady state. Analogous

\footnotetext{
${ }^{4}$ As with government purchases, a CES functional form would also have these advantages and would not change any of our main points below, but would complicate the notation and setup of the model unnecessarily. Galí (1994) and Horvath (2000) use a CES specification for aggregate investment. Note that nominal investment can easily be defined as $Y_{t}-P_{C t} C_{t}-P_{G t} G_{t}$, but to decompose this into aggreate real investment and a price index for investment is less straightforward for functional forms more general than CES.

${ }^{5}$ In the examples below, we will use standard Cobb-Douglas production functions for the $F_{i}$, but we do not make that assumption here in order to emphasize that the results below (such as the second-order nature of the relative productivity channel, in Proposition 3) hold for general functions $F_{i}$ and are not due to restrictions imposed by the Cobb-Douglas functional form.
} 
to the baseline one-sector model, we assume that technology $\left\{A_{i t}\right\}$ in each sector $i$ follows an exogenous, stationary Markov process.

Unlike the aggregate quantities defined up to this point (capital, labor, consumption, investment, and government purchases), each of which has a clear and unambiguous theoretical aggregate in the model, there is no theoretically unambiguous definition of aggregate output in Multi-sector Model II. ${ }^{6}$ Aggregate nominal output, of course, satisfies $P_{t} Y_{t}=\sum p_{i t} y_{i t}$, but one must still take a stand on how to decompose aggregate nominal output into aggregate real output and price level components.

In this paper, we define aggregate real output and the aggregate price level using Fisher ideal indexes, that is:

$$
\begin{aligned}
Y_{t} & \equiv \sqrt{\left(\frac{\sum p_{i 0} y_{i t}}{\sum p_{i 0} y_{i 0}}\right)\left(\frac{\sum p_{i t} y_{i t}}{\sum p_{i t} y_{i 0}}\right)} \cdot \sum p_{i 0} y_{i 0}=\frac{1}{P_{t}} \sum p_{i t} y_{i t} \\
P_{t} & \equiv \sqrt{\left(\frac{\sum p_{i t} y_{i 0}}{\sum p_{i 0} y_{i 0}}\right)\left(\frac{\sum p_{i t} y_{i t}}{\sum p_{i 0} y_{i t}}\right)}
\end{aligned}
$$

where a subscript of 0 denotes the base-period value of a variable. We use Fisher ideal indexes for two main reasons: First, Diewert (1993) and others have found that index to be preferable to others on theoretical grounds, and second, the U.S. Bureau of Economic Analysis currently uses Fisher ideal indexes to construct U.S. real GDP and U.S. GDP price indexes, so the Fisher ideal index also corresponds to the definition of aggregate U.S. output used in practice. ${ }^{7}$

Note also that, because Multi-sector Model II is a real model, only relative prices in each period matter. Thus, we may normalize prices in each period by the aggregate price level $P_{t}$ so as to set $P_{t}=1$ in every period, which yields the definition given in (II-4).

Sectoral Supply Equals Sectoral Demand. In addition to the above equations, the economy must also satisfy the $n$ sectoral constraints:

$$
F_{i}\left(K_{i t}, A_{i t} L_{i t}\right)=C_{t}\left(\frac{p_{i t}}{\eta_{i} P_{C t}}\right)^{-\theta}+\frac{\xi_{i}}{P_{K t}}\left(Y_{t}-P_{C t} C_{t}-P_{G t} G_{t}\right)+G_{i t}
$$

\footnotetext{
6 This difficulty it not specific to Model II, but arises for sectoral models in general.

7 In practice, the BEA "chains" the base period forward each period in the construction of real GDP and the GDP price index. In the examples below, we will not chain the base period forward for simplicity, but we will focus attention primarily on the first period or two after a shock. The definition of aggregate output in the first period correspondse exactly to the definition used by BEA for computing U.S. real GDP.
} 
which equate the supply of each good $i$ to its demand $\left(C_{i t}+I_{i t}+G_{i t}\right)$ at each time $t .{ }^{8}$

Equilibrium in Multi-sector Model II. Given $K_{i t}, A_{i t}$, and $G_{i t}, i=1, \ldots, n$, the representative agent chooses state-contingent plan for $\left\{L_{i t}\right\}$ and $\left\{C_{i t}\right\}$ that maximize (II1) subject to the inividual's asset accumulation equation:

$$
\begin{aligned}
K_{t+1} & =\left(1+r_{t}\right) K_{t}+\frac{1}{P_{K t}}\left((1-\tau) w_{t} L_{t}-P_{C t} C_{t}+T_{t}\right) \\
\text { where } w_{t} & \equiv p_{i t} A_{i t} \partial F_{i} / \partial(A L) \\
r_{t} & \equiv\left(1 / P_{K t}\right)(1-\tau) \sum\left(K_{i t} / K_{t}\right) p_{i t} \partial F_{i} / \partial K-\delta
\end{aligned}
$$

and the transversality condition (I-6). Note that the wage $w_{t}$ is the same across all sectors $i$, while the return to capital $r_{t}$ is the weighted average of the returns to capital across all of the various sectors $i{ }^{9}$ The representative agent takes as given the histories of all relevant variables up to time 0 , the exogenous stochastic processes for $\left\{A_{i t}\right\}$ and $\left\{G_{i t}\right\}$, and the stochastic future paths of the vector $\left\{w_{t}, r_{t}, T_{t}, P_{C t}, P_{K t}\right\}$. An equilibrium of the model is a solution to the agent's problem above taking as given the stochastic, aggregate time paths for $\left\{w_{t}, r_{t}, T_{t}, P_{C t}, P_{K t}\right\}$ that results from agents' consumption and labor supply rules and equations (II-2) through (II-6).

\subsection{Solution Method}

The assumptions of a CES form for consumption and perfect labor mobility imply that agents' maximization problem for Model II is separable into two distinct stages: first an intertemporal problem and then an intratemporal problem. In particular, agents' choices of $C_{i t}$ and $L_{i t}$ do not affect their intertemporal decision problem other than through the aggregate quantities $C_{t}$ and $L_{t}$. We can thus first solve for agents' optimal choices of $\left\{C_{t}\right\}$ and $\left\{L_{t}\right\}$ across time as if we were in a one-sector model, and then allocate consumption and labor across sectors $i$ once the aggregate $C_{t}$ and $L_{t}$ have been chosen.

The intratemporal allocation problem is then straightforward, given the desired levels of $C_{t}$ and $L_{t}$ : the $C_{i t}$ are distributed across goods according to their weights in the optimal

\footnotetext{
${ }^{8}$ The capital stocks $K_{i t}$ and technologies $A_{i t}$ are given and the production functions $F_{i}$ and demand functions $C_{i t}, I_{i t}$, and $G_{i t}$ are continuous, so for any given $L_{i t}$, so such an equilibrium vector of prices $p_{i t}$ that satisfies (II-5) at time $t$ exists (e.g., Arrow and Hahn, 1971).

${ }^{9}$ The return to capital may differ across sectors ex post due to shocks. Agents are representative, so each agent's assets are divided across sectors in the same proportion as are the $K_{i t}$, and earn return $r_{t}$. The $\left(1 / P_{K t}\right)$ term in the interest rate comes from the equilibrium requirement for consistency with the aggregate constraint (II-3).
} 
CES bundle, and the $L_{i t}$ are allocated to equalize the marginal product of labor across sectors, by perfect labor mobility. At the end of the period, agent's assets $K_{t+1}$ are likewise allocated across sectors to equalize the expected marginal product of capital in period $t+1$; as with labor $L_{i t}$, this follows from the perfect end-of-period mobility of capital.

Numerical Solution Procedure. Closed-form solutions to models I and II cannot be obtained in general. The solution procedure we use is a generalization of the standard log-linearization procedure in King, Plosser, and Rebelo (1988), among others. We require a generalization because the variation in sectoral output, employment, and prices (and later, capital utilization) can be very large at the sectoral level-10 or even 20 percent - so that a solution procedure that linearizes all variables from the outset is suspect.

To remedy this problem with the standard procedure, we solve the model nonlinearly for the first few periods after a shock and linearize only after the effects of the shock have died down to a point where the linearization seems reasonable. Thus, if a shock hits the economy in period $t$, the equations of the model are linearized only for periods $t+k$ and beyond, for some positive integer $k$. This allows us to easily obtain an accurate solution for the infinite-horizon problem while still preserving the possibly important nonlinearities of the model's equations in periods $t$ through $t+k-1$. By choosing $k$ appropriately, we can ensure that the effects of the initial shock have died down sufficiently that a linearization of these later periods is a reasonable approximation.

More specifically, we choose a value for $k$, guess values for the state and costate variables in periods $t$ through $t+k-1$ that are consistent with the nonlinear equilibrium conditions of the model, and then solve the model linearly from time $t+k$ forward. ${ }^{10} \mathrm{We}$ evaluate the error in the costate variables at time $t+k$ between our guess and the linear stability requirement, guess new values for variables in periods $t$ through $t+k-1$, and iterate until we achieve convergence. Finally, we check that the linear approximation is adequate by increasing $k$ by 1 and verifying that the solution does not change appreciably. Additional details are provided in Appendix A.

\section{The Relative Price Channel}

In a model with sectoral heterogeneity, even standard macroeconomic shocks have first-

\footnotetext{
${ }^{10}$ As discussed in the previous section, the intertemporal vs. intratemporal separability of the model means we effectively only have to solve for the aggregate variables in this latter stage.
} 
order effects on the relative prices of sectoral goods. Changes in relative prices, to the extent that they affect the relative prices of consumption, investment, and government purchases, in turn have first-order effects on agents' decision rules and hence aggregate consumption, investment, output, and other variables.

Intuitively, a shock that stimulates investment leads to an increase in the relative prices of goods that are relatively investment-specific, which in turn tends to dampen the investment effects of the shock and instead channel agents' responses into increased consumption and leisure. Similarly, an exogenous increase in government purchases leads to increases in the relative prices of goods that are relatively government-purchases-specific, which in turn lowers the relative prices of consumption and investment that agents face, which channels agents' responses into increased consumption, increased investment, and increased labor supply. ${ }^{11}$ We now prove this intuition and provide concrete examples.

\subsection{Theory}

We prove that the first of the two effects described above (aggregate shocks have first-order effects on relative prices) exists and is first-order as follows. It is not hard to show that the supply of good $i$, given by the left-hand side of equation (II-5), is first-order and increasing in the relative price $p_{i t}$, taking aggregate quantities as given. Similarly, demand for good $i$, given by the right-hand side of (II-5), is either first-order and decreasing (if $\theta>0, \eta_{i}>0$, and $\eta_{j}>0$ for some $j \neq i$ ) or constant in the relative price $p_{i t}$. We can use these observations to prove that, in an economy with sectoral heterogeneity, standard economic shocks require first-order adjustment in relative prices $p_{i t}$ to maintain equilibrium: ${ }^{12}$

Proposition 1. Consider an economy described by Model II with $n>1$ sectors. An exogenous change in sectoral government purchases $G_{j t}$ or sectoral technology $A_{j t}$ in sector $j$ has a first-order effect on relative prices $p_{i t}$ in general. Moreover, if there exists some $(i, j)$ such that $\eta_{i} \neq \eta_{j}, \xi_{i} \neq \xi_{j}, \gamma_{i} \neq \gamma_{j}$, or $\frac{\left(\partial F_{i} / \partial(A L)\right)^{2}}{\partial^{2} F_{i} / \partial(A L)^{2}} \neq \frac{\left(\partial F_{j} / \partial(A L)\right)^{2}}{\partial^{2} F_{j} / \partial(A L)^{2}}$, then a uniform exogenous change in government purchases $G_{i t}$ or a uniform change in technology $A_{i t}$ across all sectors $i$ has a first-order effect on relative prices $p_{i t}$ in general.

\footnotetext{
${ }^{11}$ In other words, an increase in $P_{G t}$ is an increase in the price of what agents produce $(Y)$ relative to what they consume $(C$, and future $C$ through $I)$. Thus, agents view an increase in $P_{G t}$ as essentially a technology shock, because it literally is a productivity shock in terms of agents' numeraire.

12 Proposition 1 is also generalizable to essentially any shock one might wish to consider, including shocks to transfers $T_{t}$ or taxes $\tau$, "taste" shocks to the $\eta_{i}$ or $v$, investment composition shocks to the $\xi_{i}$, or government purchases composition shocks to the $\gamma_{i}$.
} 
Proof: See Appendix B.

Intuitively, Proposition 1 should not be surprising. Indeed, one would expect that only under extremely restrictive conditions would it be true that equilibrium prices would move in perfect unison in response to shocks. The role of Proposition 1 is to formalize this intuition for the dynamic, stochastic case presented by Model II, where standard aggregation theorems from microeconomics do not necessarily apply.

We now show that changes in relative prices in turn have first-order effects on the equilibrium of the aggregate variables of the model:

Proposition 2. Consider an economy described by Model II with $n>1$ sectors.

(i) Suppose that the equilibrium value of $P_{K t}, P_{C t}$, or $P_{G t}$ changes. Then, in general, the equilibrium values of $C_{t}, I_{t}, L_{t}$, and $Y_{t}$ must also change. Moreover, this relationship is first-order.

(ii) Suppose that the equilibrium value of $p_{i t}$ changes for some sector $i$. If the coefficients $\xi_{j}, \eta_{j}$, or $\gamma_{j}, j=1, \ldots, n$, are such that any of $P_{K t}, P_{C t}$, or $P_{G t}$ change as a result, then the equilibrium values of $C_{t}, I_{t}, L_{t}$, and $Y_{t}$ must also change by part (i). Alternatively, if $\eta_{i}>0$ and $\eta_{j}>0$ for some $j \neq i$, then the equilibrium values of $C_{t}, I_{t}$, $L_{t}$, and $Y_{t}$ must also change, and this relationship is first-order.

Proof: See Appendix B.

Together, Propositions 1 and 2 form a kind of "aggregation impossibility theorem" for DSGE models when the economy consists of more than one sector and those sectors are heterogeneous for at least one of consumption, investment, or government purchases. Even though Model II presents a near-best-cast scenario for macroeconomic aggregation, with clear and unambiguous theoretical aggregates for consumption, investment, government purchases, labor, and capital, it is nonetheless the case that the transmission of aggregate shocks to aggregate quantities in the model is transformed in important, first-order ways by the distributional properties of the model. Unfortunately, it is precisely these distributional properties that macroeconomists would prefer to abstract away from (and would hope have only minor, second-order effects) in the specification of the model.

\subsection{Examples}

We now demonstrate the practical importance of the relative price channel and Propositions 1 and 2 by means of two examples: a 1\% aggregate technology shock (i.e., a $1 \%$ 
exogenous change in $A_{i t}$ for all sectors $i$ ), and a $4 \%$ exogenous shock to government purchases.

Technology Shock. Figure 1 graphs side-by-side the impulse respones of Baseline Model I and Multi-sector Model II to a $1 \%$ aggregate technology shock. ${ }^{13}$ For simplicity, we assume that Model II has just two sectors, that production functions are Cobb-Douglas, and that the utility kernel has the logarithmic form (including $v$, which we set to $v\left(1-L_{t}\right) \equiv$ $\left.\log \left(1-L_{t}\right)\right)$. The baseline parameters for both models are listed at the bottom of the figure and are standard. The interesting feature of Model II is that sector 2 of the model produces only the investment good while sector 1 produces the good that is used for consumption and government purchases. If not for this key difference, Model II would be essentially identical to Model I, and their aggregate implications would be identical.

The impulse responses of Model I, given by the white bars in Figure 1, are standard: labor increases moderately, output increases by $1 \%$ plus two-thirds of the labor increase, consumption increases moderately, and investment increases very strongly, by about $4 \%$. The gray bars in Figure 1 plot the impulse responses to the two-sector implementation of Model II to the same $1 \%$ technology shock.

The key difference between Models I and II is that in the latter, the relative price of investment increases in response to the strong rise in investment demand after the shock, by about $0.5 \%$ relative to the non-investment good (not shown in the figure). The difference between the gray bars and the white bars in Figure 1 thus represents the effects of the relative price channel operating through the relative price of investment. As can be seen in the figure, this leads to exactly the effects predicted earlier: a fall in investment and an increase in consumption and leisure (all relative to Model I). ${ }^{14}$

The direct effects of changes in relative prices in Model II last for only one period, due to the assumption that capital is freely mobile at the end of each period, which allows relative prices across all sectors to re-equalize at that time. ${ }^{15}$ Introducing additional frictions (such as adjustment costs to capital) into the model would give the relative price

\footnotetext{
13 The technology shock is assumed to have an $\mathrm{AR}(1)$ persistence with autoregressive parameter 0.65 , comparable to King, Plosser, and Rebelo (1988) and postwar U. S. data.

14 The presence of a government sector in this example has relatively little effect on the basic results. For example, dropping the government sector from the model in Figure 1 leads to slight changes in the numbers in the figure, but does not alter any of the basic patterns in the figure or the importance of the relative price channel. Similarly, the basic results in our other examples below (excluding the government purchases shock example) are essentially unaltered if we drop the government sector from the model entirely.

15 The effects of the relative price channel do not completely disappear after the first period because
} 


\section{Figure 1: Responses of Models I And II to a 1\% Technology Shock}

White bars: Baseline (KPR) Model I, Gray bars: Two-Sector Implementation of Model II, difference between the two sets of bars represents the Relative Price Channel
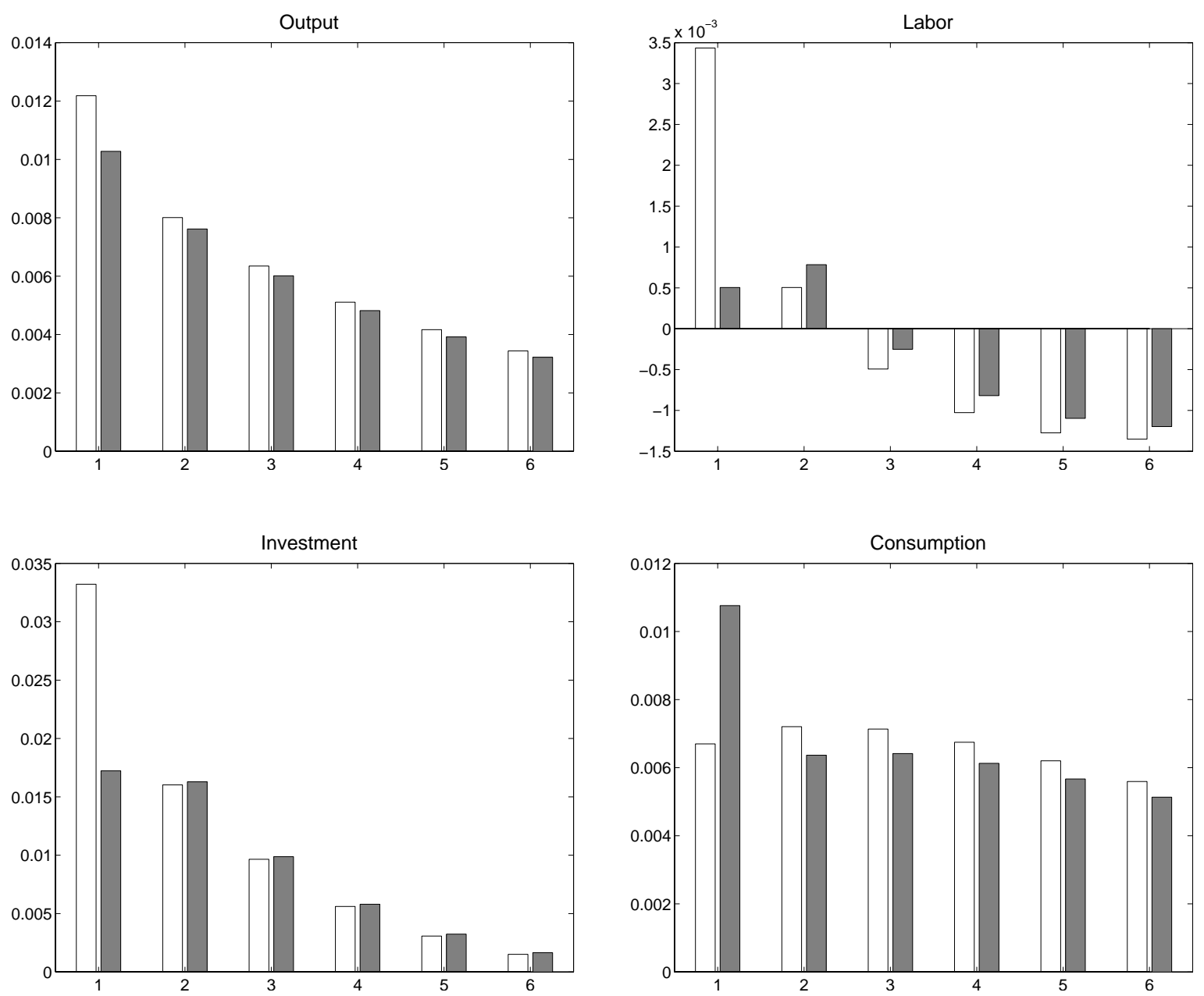

Baseline Parameters, All Models:

$$
\begin{array}{llrl}
\alpha=.65 & \nu & =1 \\
\beta=.99 & \sigma & =1 \\
\delta=.1 & \tau & =.2 \\
& \mathrm{G} / \mathrm{Y} & =.2
\end{array}
$$

Sectoral Parameters, Model II:

$$
\begin{aligned}
\alpha_{i} & =[.65, .65] \\
C_{i} / C & =[1,0] \\
I_{i} / I & =[0,1] \\
G_{i} / G & =[1,0] \\
\hat{A}_{i} & =[.01, .01]
\end{aligned}
$$

the change in investment in the first period causes the capital stock in the second period and beyond to 
channel a more realistic degree of persistence, but at the cost of losing the exact correspondence between multi-sector Model II and the plain-vanilla Model I, which would make comparing the two models - and isolating the relative price channel-much more difficult.

Government Purchases Shock. Figure 2 considers the case of an exogenous $4 \%$ increase in government purchases, which corresponds to a one-standard-deviation shock to this variable over the postwar period. ${ }^{16}$ Again, we consider a two-sector version of Model II, with all production functions Cobb-Douglas and log utility, with parameter values given at the bottom of the figure. In contrast to the previous example, in this case we assume that the government purchases good is produced in sector 2 while sector 1 produces the good used for consumption and investment. Again, if not for this key difference, the two models would be identical and have identical aggregate implications.

The impulse responses of Model I to the shock (the white bars) are standard: an increase in labor, an increase in output, and a fall in consumption and investment as agents react to the negative wealth effect of increased government resource consumption. The gray bars plot the responses of Model II to the same $4 \%$ government purchases shock, although in this case the increase in government purchases is concentrated entirely in sector 2 .

In this example, it is now the relative price of government purchases that increases in response to the strong rise in demand, by about $2.3 \%$ relative to the price of consumption (not shown in the figure). The difference between the gray and white bars, which represents the effects of the relative price channel, is exactly as predicted earlier: an increase in labor, an increase in output two-thirds the size of the rise in labor, a slight increase in consumption, and a dramatic rise in investment. ${ }^{17}$ Note that, in contrast to Figure 1 , the relative price channel here generally amplifies rather than attenuates the effects of the driving shock. Although the effects of the relative price channel vary across examples, they vary in a way that is intuitive, as we have tried to emphasize in each example.

Most importantly, the effects of the relative price channel on the aggregate variables

differ, which in turn leads to differences in consumption, labor, investment, and output in each period going forward.

16 The government purchases shock is assumed to have $\operatorname{AR}(1)$ persistence with autoregressive parameter .75, as measured in postwar U. S. data.

17 The effects of the relative price channel on labor, consumption, and investment in Figure 2 do in fact precisely match the effects of a $0.5 \%$ exogenous technology shock to Model I, as in the intuition in footnote 7 . They do not, however, match the white bars in Figure 1, because the technology shock there is assumed to have $\operatorname{AR}(1)$ persistence, while the relative price change in Figure 2 lasts for only one period because relative prices re-equalize after one period. 
Figure 2: Responses of Models I and II to A 4\% Government Purchases Shock White bars: Baseline (KPR) Model I, Gray bars: Two-Sector Implementation of Model II difference between the two sets of bars represents the Relative Price Channel
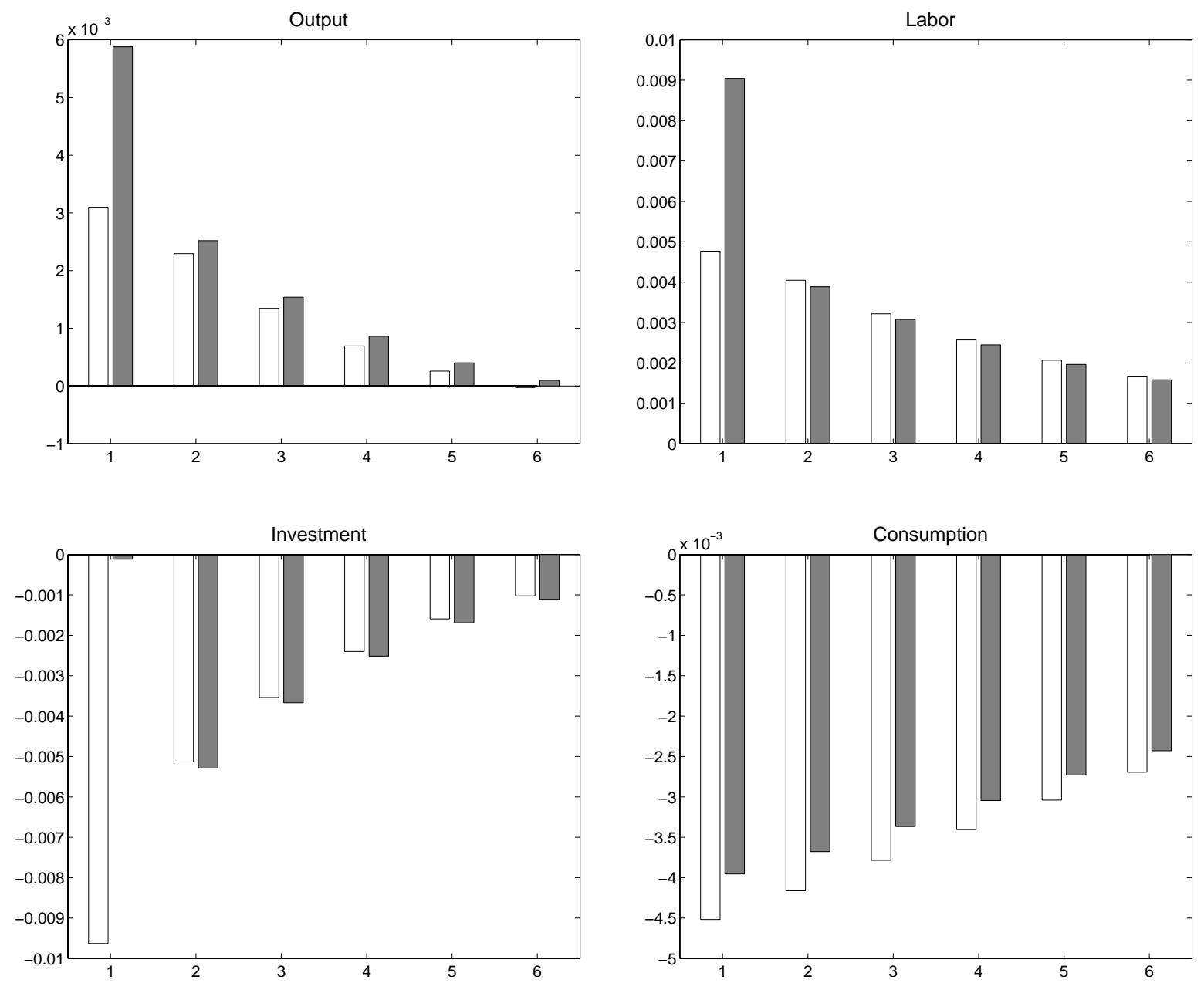

Sectoral Parameters, Model II:

$$
\begin{aligned}
\alpha_{i} & =[.65, .65] \\
C_{i} / C & =[1,0] \\
I_{i} / I & =[1,0] \\
G_{i} / G & =[0,1] \\
\hat{G}_{i} & =[0, .04]
\end{aligned}
$$


in these examples arose not from any bells and whistles that were added to the model, but simply from the existence of sectoral heterogeneity. Sectoral heterogeneity itself has important implications for the propagation of aggregate shocks in the model.

\section{The Relative Productivity Channel}

We define the relative productivity channel to be any effect on aggregate output or other aggregate variables arising solely from changes in the sectoral distribution of inputs to production (as opposed to the effects of changes in the aggregate quantities of inputs, which are already captured by the standard one-sector analysis.) For example, Basu and Fernald $(1997,2002)$ show that shifting inputs from a sector with decreasing or constant returns to scale to a sector with higher returns to scale gives the appearance of large increasing returns to scale and procyclical productivity at the aggregate level.

\subsection{Theory}

It has sometimes been suggested that there is, in effect, such a relative productivity channel in standard multi-sector models such as Model II. For example, Davis (1987) and Phelan and Trejos (2000) emphasize that the distribution of quasi-fixed factors (e.g., capital) prior to a shock automatically becomes suboptimal ex post. This suboptimal allocation implies a lower level of aggregate output and productivity than could be obtained in the absence of such a shock, so that unusually large reallocative shocks look like recessions.

While this argument is appealing, the fact that the aggregate effects of such a shock are always negative, regardless of the direction of the reallocation, suggests that these effects are likely to be second-order. In fact, this can be demonstrated as follows:

Proposition 3. Consider an economy described by Model II that is at steady state. Then a change in the allocation of the $L_{i t}$ that has no effect on the aggregate quantity of labor $L_{t}$ also has no first-order effect on total output $Y_{t}$.

ProOF: Let the absence of a time subscript denote steady-state values, let $\alpha_{i}$ denote labor's share $\left(w L_{i} / p_{i} Y_{i}\right)$ in sector $i$, let $\alpha$ denote labor's aggregate share $(w L / Y)$, and let a circumflex over a variable denote log-deviation from steady state. Then:

$$
\hat{Y}_{t}=\sum \frac{p_{i} Y_{i}}{Y} \hat{Y}_{i t}
$$




$$
\begin{aligned}
& =\sum \frac{p_{i} Y_{i}}{Y} \alpha_{i}\left(\hat{A}_{i t}+\hat{L}_{i t}\right)+\sum \frac{p_{i} Y_{i}}{Y}\left(1-\alpha_{i}\right) \hat{K}_{i t} \\
& =\sum \frac{p_{i} Y_{i}}{Y} \alpha_{i} \hat{L}_{i t} \quad \text { assuming no shocks to } A_{i t}, \text { and } K_{i t} \text { fixed } \\
& =\alpha \hat{L}_{t}
\end{aligned}
$$

Proposition 3 states that there is no relative productivity channel, as described above, for the $L_{i t}$ - at least not to first order under the standard assumptions of Model II. ${ }^{18}$ The intuition behind this result is very simple, and very general: In steady state, the marginal products of the $L_{i t}$ are equalized across sectors. Within a neighborhood of steady state, then, changes in the $L_{i t}$ all have the same effect at the margin, so that changes in the individual $L_{i t}$ can be regarded as perfect substitutes for one another. All that matters for aggregate output is the net effect on the aggregate quantity of labor $L_{t}$.

Neither adjustment costs or lags nor intermediate input linkages alters the basic conclusion of Proposition 3:

Proposition 4. Consider an economy described by Model II that is at steady state.

(i) Suppose that convex adjustment costs to labor are incorporated into Model II, so that $Y_{i t}=F_{i}\left(K_{i t}, A_{i t} L_{i t}\right)-\Gamma_{i}\left(\Delta L_{i t} / L_{i t}\right)$, where $\Gamma_{i}$ is a convex function with $\Gamma_{i}^{\prime}(0)=0$ for all $i$. Then a change in the allocation of the $L_{i t}$ that has no effect on the aggregate quantity of labor $L_{t}$ also has no first-order effect on total output $Y_{t}$.

(ii) Suppose that lags to labor adjustment are incorporated into Model II, so that $L_{i t}$ is not free to change for $k_{i} \geq 0$ periods after the incidence of a shock, $i=1, \ldots, n$. Then a change in the allocation of the $L_{i t}$ that has no effect on the aggregate quantity of labor $L_{t}$ also has no first-order effect on total output $Y_{t}$.

(iii) Suppose that intermediate inputs are incorporated into Model II, so that the sectoral production functions are given by $F_{i}\left(K_{i t}, A_{i t} L_{i t}, M_{i 1 t}, \ldots, M_{i n t}\right)$, where $M_{i j}$ denotes an input from sector $j$ into sector $i$ that can be freely varied within period $t$. Then a change in the allocation of the $L_{i t}$ that has no effect on the aggregate quantity of labor $L_{t}$ also has no first-order effect on total output $Y_{t}$.

PROOF: (i) The adjustment cost functions $\Gamma_{i}$ subtract only second-order terms from output in each sector, so the growth accounting calculation in the proof of Proposition 3 is essentially unchanged.

(ii) Clear from the growth accounting calculation in the proof of Proposition 3.

(iii) Clear from a growth accounting calculation analogous to that in the proof of Proposition 3 .

\footnotetext{
${ }^{18}$ Similarly, allowing for shocks to the $A_{i t}$ leads to no additional effects on $\hat{Y}_{t}$ other than through their effect on $\hat{A}_{t} \equiv \sum\left(L_{i} / L\right) \hat{A}_{i t}$, the weighted average of the changes in sectoral productivities, and any induced endogenous response of aggregate $L_{t}$ to the $A_{i t}$.
} 
The results of Propositions 3 and 4 are noteworthy in that they contrast quite strongly with conventional wisdom in the literature (e.g., Davis, 1987, Ramey and Shapiro, 1998, Phelan and Trejos, 2000). In particular, Propositions 3 and 4 state that reallocations are not necessarily times that look like recessions, at least not to first order in models in which the marginal products of inputs are able to equalize across sectors in steady state. Part (iii) of Proposition 4 also makes it clear that intermediate input linkages alone do not necessarily provide an amplification and propagation mechanism for shocks, at least not to first order in models in which the marginal products of those inputs are able to equalize across sectors in steady state, in contrast to the impressions given by Long and Plosser (1983) and Horvath (1998). ${ }^{19}$

One might protest that Propositions 3 and 4 hinge crucially on the assumption that marginal products of inputs are equal prior to the reallocation. If a slowly-adjusting economy is hit by two shocks in a row, for example, then the marginal products of inputs are different when the second shock hits, and Propositions 3 and 4 would no longer apply. The refutation of this argument is that the above propositions are stated in terms of logdeviations from steady state. Thus, even after multiple shocks, so long as the economy remains within a neighborhood of its steady-state equilibrium - a realistic assumption for most macroeconomic models - the conclusions of Propositions 3 and 4 continue to apply.

Second, one might question whether second-order effects in these models are not themselves important. Although exogenous shocks typically lead to movements in aggregate variables of only a few percentage points, the impact on specific sectors might be larger (indeed, this was the motivation for the $k$-period nonlinear solution procedure in Section 2.3). As we show in Figure 3 below, however, these second-order effects are unimportant in practice as well as in principle, at least for standard calibrations of Model II. ${ }^{20}$

\footnotetext{
${ }^{19}$ Indeed, Long and Plosser's (1983) result that sectoral intermediate input linkages affect aggregate output can be completely derived from an aggregate production function $Y_{t}=F\left(K_{t}, L_{t}, M_{t}\right)$, where $M_{t}$ is the input from last period's output (this timing assumption is the same as Long and Plosser's, and drives their persistence result). Dupor (2000) makes the same point (that intermediate input linkages are not important) by calculating the value function in closed form for a very simple model.

${ }^{20}$ Phelan and Trejos (2000) claim a significant effect of reallocation on aggregate productivity in their abstract ("the frictions we study can cause one time increases in productivity concentrated in one sector to be mistaken for a series of smaller, correlated aggregate productivity shocks," title page), but an examination of their paper confirms the assertion that it is second order: the shock is a $24 \%$ leap in productivity in the sector in question, the sector itself comprising one-third of the aggregate economy. The reallocative effect on aggregate productivity — the component beyond the direct average $\sum\left(L_{i} / L\right) \hat{A}_{i t}$-is less than $2 \%$.
} 
Moreover, we demonstrate below a simple and plausible modification of the model that renders the relative productivity channel operative with first-order importance, so we will propose that as a more interesting avenue for research.

Finally, one might wonder how previous authors (e.g., Rogerson, 1987, Hamilton, 1988, Ramey and Shapiro, 1998, and Phelan and Trejos, 2000) found very significant effects of sectoral reallocation, given the conclusions of Propositions 3 and 4 . The key observation is that these authors all adopt specifications for adjustment costs that are V-shaped or kinked at zero, and thus do not satisfy the assumptions of Proposition 4. For example, in Rogerson (1987), Hamilton (1988), and Phelan and Trejos (2000), labor must be unemployed for at least one period in order to relocate from one sector to another. This adjustment cost specification is kinked at zero, with no cost to increasing labor in a sector but an essentially linear cost to decreasing labor, with the adjustment cost per worker equal to the marginal product of labor. In Ramey and Shapiro (1998), it is capital that is costly to relocate, but the specification is otherwise very similar: capital must be taken off-line for one period to switch sectors and, moreover, there is a surcharge of $\gamma$ times the amount of capital relocated, which is also explicitly kinked and linear for reductions in the capital stock.

It is also worth noting that, through these linear adjustment costs, the above authors generate first-order effects of reallocation on aggregate $L_{t}$ (or $K_{t}$ ). Thus, strictly speaking, it is not the sectoral reallocation itself that drives their results so much as the large (i.e., linear) adjustment costs associated with the reallocation. This observation is not meant to detract from the importance of their results - indeed, their adjustment cost specifications may be very realistic. Nonetheless, in the present paper, we focus on the implications of sectoral heterogeneity itself (rather than adjustment costs) for the transmission of shocks to aggregate variables.

\subsection{Sectoral Capital Utilization}

As shown above, in order to generate a relative productivity channel that is of first-order importance, one must introduce a wedge into the model that drives apart the sectoral marginal products of an input to production. One way to introduce such a wedge is through imperfect competition and markups of price over marginal cost (although note 
that in order to generate a wedge across sectors, it is differences in markups that are important, rather than the markups themselves).

In the present paper, we pursue an alternative, more novel approach: that differences across sectors in the technology for utilizing capital introduce a steady-state wedge across sectors. In addition to being more novel, numerous empirical studies have found that, once variable capital utilization is taken into account, there is little evidence of increasing returns to scale and markups at the sector or plant level (e.g., Griliches and Ringstad, 1971, Burnside, Eichenbaum, and Rebelo, 1995 and 1996, Basu, 1996, and Baily, Hulten, and Campbell, 1992). ${ }^{21}$ By contrast, numerous empirical studies document the importance of variable capital utilization over the business cycle at all levels of aggregation (e.g., Burnside, Eichenbaum, and Rebelo, 1995, Basu, 1996, and Shapiro, 1996). According to Shapiro, over $40 \%$ of the cyclical variation in manufacturing employment comes from work on evening and late shifts. More importantly for the present analysis, Shapiro shows that cyclical variation in the workweek of capital varies greatly even across sectors within manufacturing. Although data on capital utilization in non-manufacturing sectors is scarce, it seems reasonable that differences in the marginal returns to utilization would be even greater when one considers the economy more broadly.

Before turning to the model, the intuition for the approach is as follows. Although labor and long-run capital mobility ensure that the marginal products of these factors are equalized across sectors in steady state, the marginal product of utilization can differ across sectors because the utilization of capital is inherently nontradeable. One sector of the economy could be characterized by relatively high returns to utilization while another might be characterized by relatively low returns, and these will never be equalized because the utilization rate is internal to each sector and cannot be traded between the two. ${ }^{22}$ This is despite the fact that, in steady state, the marginal products of capital in the two sectors will be equalized.

For simplicity, we drop the general production functions $F_{i}\left(K_{i t}, A_{i t} L_{i t}\right)$ and focus on

\footnotetext{
${ }^{21}$ From growth accounting, marginal returns to scale $\gamma$ equals $\left(1-s_{\pi}\right)$ times the markup $\mu$, where $s_{\pi}$ is the average revenue share of economic profits, so returns to scale and markups are not necessarily identical. However, a significant difference between the two requires a significant share of economic profits in the sector, which is generally at odds with the data (Rotemberg and Woodford, 1995, Basu and Fernald, 1997).

22 For example, one might think of Durable Goods Manufacturing as having relatively high returns to extra shifts and overtime and Services and Retail Trade as having substantial diminishing returns.
} 
the Cobb-Douglas case. Capital utilization $U_{i t}$ is incorporated as follows:

$$
Y_{i t}=A_{i t}\left(U_{i t}^{\omega_{i}} K_{i t}\right)^{1-\alpha_{i}} L_{i t}^{\alpha_{i}}
$$

This is similar to the one-sector models of Greenwood, Hercowitz, and Huffman (1988) and Burnside and Eichenbaum (1996), except for the introduction of the coefficients $\omega_{i} \in$ $[0,1]$, which determine the marginal product of utilization within each sector: low (high) values of $\omega_{i}$ correspond to small (large) returns to the utilization of capital, which leads utilization to vary less (more) in response to shocks to the sector. ${ }^{23}$ Previous models incorporating capital utilization have simply taken $\omega_{i}=1$, the implicit assumption being that the marginal product of new capital (e.g., a new factory or store) and the marginal product of utilization (e.g., an extra shift at an existing installation) are equal. Although this assumption might be reasonable for some sectors within manufacturing, it is more difficult to justify in general. For example, capital in the Services or Retail Trade sector is probably significantly less productive late in the evening, when many customers are home or asleep; it thus seems reasonable that these sectors would have values for $\omega_{i}$ significantly less than $1 .^{24}$

Given the functional form assumptions in (7), profit maximization and the short-run fixity of capital $K_{i t}$ yield:

$$
\begin{aligned}
& L_{i t}=A_{i t}^{1 /\left(1-\alpha_{i}\right)}\left(\frac{w_{t}}{\alpha_{i} p_{i t}}\right)^{-1 /\left(1-\alpha_{i}\right)} U_{i t}^{\omega_{i}} K_{i t} \\
& Y_{i t}=A_{i t}^{1 /\left(1-\alpha_{i}\right)}\left(\frac{w_{t}}{\alpha_{i} p_{i t}}\right)^{-\alpha_{i} /\left(1-\alpha_{i}\right)} U_{i t}^{\omega_{i}} K_{i t}
\end{aligned}
$$

Utilization must have some cost if it is to be finite in equilibrium. Following Greenwood, Hercowitz, and Huffman (1988) and Burnside and Eichenbaum (1996), we take this cost directly out of the capital stock, in the form of increased depreciation $\delta_{i t} \equiv \delta_{i}\left(U_{i t}\right)$,

\footnotetext{
${ }^{23}$ For any value of $\omega_{i}$, we will choose units so that $U_{i}=1$ in steady state; thus, the parameter is important only for the marginal product of capital utilization.

24 Similarly, Agriculture depends heavily upon daylight and weather when making use of its capital, so that additional utilization would take place under less than optimal conditions, again resulting in $\omega_{i}<1$.
} 
where $\delta_{i}$ is an increasing function of $U_{i t}:^{25}$

$$
\delta_{i}\left(U_{i t}\right) \equiv \delta_{0 i}+\frac{\delta_{1 i}}{\phi_{i}} U_{i t}^{\phi_{i}}
$$

We require $\phi_{i}>\omega_{i}$ to ensure equilibrium. We choose the parameters $\delta_{0 i}$ and $\delta_{1 i}$ so as to set steady-state utilization $U_{i}=1$ and steady-state depreciation $\delta_{i}$ to $10 \%$ per year, as in our previous examples.

The optimal choice of $U_{i t}$ is determined by equating the marginal benefit of utilization, $\omega_{i}\left(1-\alpha_{i}\right) p_{i t} Y_{i t} / U_{i t}$, to its marginal cost, $\delta_{i}^{\prime} K_{i t} P_{K t}$, yielding:

$$
\delta_{1 i} U_{i t}^{\phi_{i}}=\omega_{i}\left(1-\alpha_{i}\right) \frac{p_{i t}}{P_{K t}} \frac{Y_{i t}}{K_{i t}}
$$

Substituting (9) into (11) gives $U_{i t}$ as a function of the prices and technology faced by the firm:

$$
U_{i t}=\left(\frac{\omega_{i}\left(1-\alpha_{i}\right)}{\delta_{1 i}}\right)^{1 /\left(\phi_{i}-\omega_{i}\right)}\left(\frac{p_{i t}}{P_{K t}}\right)^{1 /\left(\phi_{i}-\omega_{i}\right)} A_{i t}^{1 /\left(\left(1-\alpha_{i}\right)\left(\phi_{i}-\omega_{i}\right)\right)}\left(\frac{w_{t}}{\alpha_{i} p_{i t}}\right)^{-\alpha_{i} /\left(\left(1-\alpha_{i}\right)\left(\phi_{i}-\omega_{i}\right)\right)}
$$

We can now specify Variable-Utilization Models III and IV as follows (Model III corresponds to a one-sector version $\left(n=1, \omega_{1}=1\right)$, analogous to Burnside and Eichenbaum (1996)):

$$
\begin{gathered}
\text { Preferences: } \quad E_{0} \sum_{t=0}^{\infty} \beta^{t} \frac{C_{t}^{1-\sigma}}{1-\sigma} v\left(1-L_{t}\right) \\
\text { where } C_{t} \equiv\left[\sum \eta_{i} C_{i t}^{(\theta-1) / \theta}\right]^{\theta /(\theta-1)} \\
P_{C t} \equiv\left[\sum \eta_{i}^{\theta} p_{i t}^{1-\theta}\right]^{1 /(1-\theta)} \\
\text { Government: } \tau Y_{t}=G_{t}+T_{t} \\
\text { where } G_{t} \equiv \sum p_{i t} G_{i t} \\
P_{G t} \equiv \sum \gamma_{i} p_{i t} \\
K_{t+1}=\left(1-\delta_{t}\right) K_{t}+\frac{1}{P_{K t}}\left(Y_{t}-P_{C t} C_{t}-P_{G t} G_{t}\right)
\end{gathered}
$$

\footnotetext{
${ }^{25}$ An alternative approach, followed by Lucas (1970) and Ramey and Shapiro (1998), is to introduce convex costs of utilization into agents' utility functions (i.e., working at night is unpleasant). By contrast, the approach in this paper imposes costs of utilization directly on agents' wealth through equation (10). These two approaches can be regarded as equivalent via a "compensating variation" argument-i.e., agents are indifferent between having the costs deducted out of their wealth or out of their leisure, since the overall effect on their budget constraint is the same.
} 


$$
\begin{aligned}
\text { where } \delta_{t} & \equiv \sum \frac{K_{i t}}{K_{t}} \delta_{i t}\left(U_{i t}\right) \\
P_{K t} & \equiv \sum \xi_{i} p_{i t}
\end{aligned}
$$

As before, the $p_{i t}$ are determined by supply and demand in each sector:

$$
A_{i t}^{1 /\left(1-\alpha_{i}\right)}\left(\frac{w_{t}}{\alpha_{i} p_{i t}}\right)^{-\alpha_{i} /\left(1-\alpha_{i}\right)} U_{i t}^{\omega_{i}} K_{i t}=C_{t}\left(\frac{p_{i t}}{\eta_{i} P_{C t}}\right)^{-\theta}+\frac{\xi_{i}}{P_{K t}}\left(Y_{t}-P_{C t} C_{t}-P_{G t} G_{t}\right)+G_{i t}
$$

An equilibrium in this model is defined as before, with the addition of the capital utilization profit-maximization condition (11). Note that agents are representative, and hence hold capital assets that are distributed across sectors in the same proportions as capital is in the aggregate economy, so that the given average depreciation rate is the appropriate one for computing agents' realized net rate of return on assets in equation $(\mathrm{I}-5)^{\prime}$.

\subsection{Examples}

We demonstrate the practical importance of Propositions 3 and 4, and of a wedge in the model such as sectoral differences in the returns to utilizing capital, by means of two examples: a pure sectoral shift, and a sectoral technology shock.

Pure Sectoral Shift. The easiest way to isolate the effects of the relative productivity channel is through a pure sectoral shift. Figure 3 thus considers the example of a pure shift in consumption-i.e., an exogenous shift in consumer's preferences $\eta_{i}$ from sector 1 to sector 2 in a two-sector implementation of Multi-Sector Models II and IV (results are very similar for a pure shift of government purchases from the first sector to the second). Impulse responses for one-sector Models I and III are not presented, and would be identically zero anyway, since the purely reallocative shock being considered here does not show up in a one-sector context. 
Parameter values for the models are specified at the bottom of Figure 3. Models II and IV in this example each comprise two sectors, with consumption, investment, and government purchases all divided equally between the two. This is to make the two sectors as similar as possible, the only difference between them being their ability to utilize capital (in Model IV; in Model II without capital utilization, the two sectors truly are identical), with sector 1 having very little ability to benefit from utilization $\left(\omega_{1}=.25\right)$, and sector 2 having full benefits of utilization $\left(\omega_{2}=1\right)$. The utilization cost parameter $\phi_{i}$ is taken to be 1.6 for both sectors, as calibrated by Burnside and Eichenbaum (1996) for aggregate data.

Figure 3 makes it clear that there is no relative productivity channel in Model II (gray bars): a reallocation of inputs from one sector to the other leads to essentially no effect on aggregate output. ${ }^{26}$ There is a small effect on aggregate consumption owing to the relative price channel, since the demand shift toward sector 2 drives up the price of the good in sector 2, but the effect is second-order in this example (as can be seen by considering the reverse shift, which would lead to the same aggregate effect). The effects on output, labor, and investment are correspondingly second-order as well. These conclusions cannot be altered simply by introducing variable capital utilization into each sector $\left(\omega_{i}=1, i=1,2\right)$, since the underlying symmetry of the model remains: any increase in production in sector 2 is simply met by an equal and opposite decrease in production in sector 1 . The effects on the aggregates in this case remain second-order and are tiny (not shown).

The introduction of a wedge into the model, however, suddenly causes the reallocation to have significant effects, for the reasons discussed above. This can be seen in the response of Model IV (black bars) to the same reallocative shock. The key observation is that sector 2 has a much greater ability to vary its capital utilization than does sector 1 so, in response to the consumption demand shift, sector 2 can increase production by relatively more at relatively low cost, while sector 1 can only decrease production slightly and reaps only a slight cost savings by doing so. The result is that production expands considerably in sector 2 while shrinking by only a small amount in sector 1. Aggregate output rises, and aggregate labor rises because of the high-wage opportunities created by sector 2 .

\footnotetext{
26 This result is confirmed by simulations of other shocks as well.
} 
Figure 3: Responses of Multi-Sector Models II And IV to a $1 \%$ Consumption Shift

Gray bars: Model II (no utilization), Black bars: Model IV (capital utilization wedge), difference between the two represents Change in Aggregate Capital Utilization plus the Relative Productivity Channel
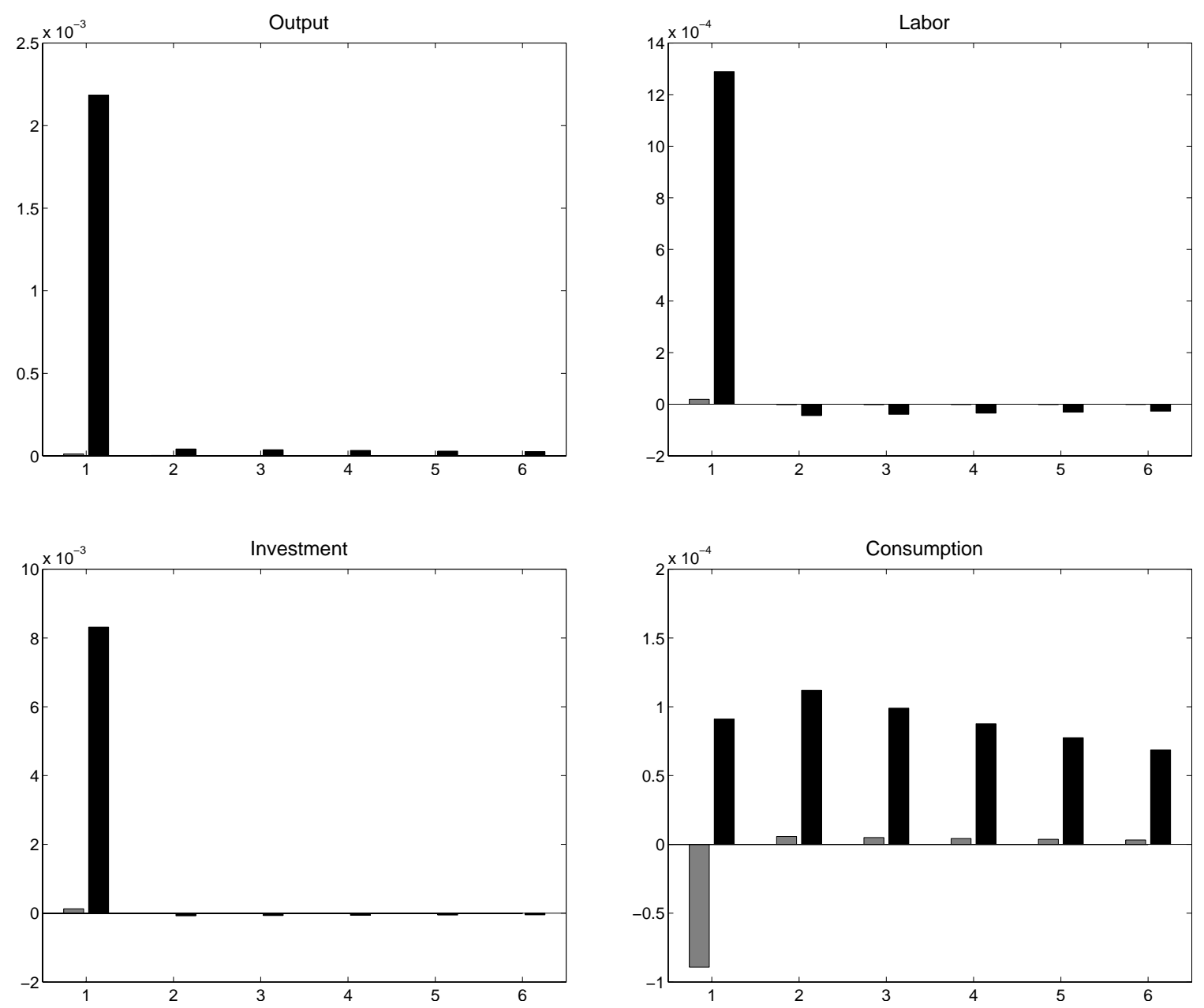

Sectoral Parameters

\begin{aligned} \hline$\theta & =.5 & C_{i} / C & =[0.5,0.5] \\ \alpha_{i} & =[.65, .65] & I_{i} / I & =[0.5,0.5] \\ \omega_{i} & =[.25,1] & G_{i} / G & =[0.5,0.5] \\ \phi_{i} & =[1.6,1.6] & \hat{C}_{i} & =[-.01, .01]\end{aligned}$


Aggregate output in Figure 3 rises by much more than two-thirds the increase in labor input for two reasons: First, there is a $0.14 \%$ increase in the average utilization of capital across the economy (not shown), and second, there is a $0.11 \%$ increase in aggregate total factor productivity above and beyond the effects of the aggregate change in capital utilization-i.e., the utilization-adjusted aggregate Solow residual, $\hat{Y}-\alpha \hat{L}-(1-\alpha) \hat{K}-$ $\omega(1-\alpha) \hat{U}$, which accounts for all aggregate inputs including (aggregate) capital utilization, is $0.11 \%$. This effect on aggregate, utilization-adjusted TFP arises because an input (capital utilization) has effectively been shifted from a sector with low marginal returns to that input to one with high marginal returns. The combined effect of the changes in aggregate utilization and TFP on output is $.13 \% .^{27}$ Note that aggregate TFP in this example is procyclical even though the shock itself was completely nontechnological in nature and even though we have controlled for (aggregate) capital utilization when measuring TFP.

Sectoral Technology Shock. As a second example, Figure 4 considers the case of a sectoral technology shock. In Figure 1 in the previous section, we considered a broad-based, aggregate technology shock in order to isolate the effects of the relative price channel, but such uniform, aggregate shocks have been criticized (e.g., Summers, 1986) for being rarely observed in practice. In Figure 4, we consider instead the example of a sector-specific, rather than an aggregate, technological innovation, for which examples are more readily available.

The economy is divided into three sectors, with one sector specializing in each of consumption, investment, and government purchases. With a nod toward recent innovations in the computer and communications industries, the technology shock is assumed to occur in the investment-goods-producing sector. ${ }^{28}$ The scale of the shock $(3.95 \%)$ is chosen so that the average, economywide innovation in TFP is $1 \%$, and thus the response of Baseline Model I to the shock of this example is the same as it was for the $1 \%$ aggregate productivity shock in Figure 1.

Impulse responses for Models I (white), II (light gray), III (dark gray), and IV (black) are all presented in Figure 4 for comparison. The parameters of the one-sector

\footnotetext{
${ }^{27}$ This is capital's share times the change in utilization times the average effectiveness of that utilization (average $\omega_{i}$ ), plus the change in TFP.

28 This example is thus similar to Greenwood, Hercowitz, and Krusell (2000), who consider the importance of investment-good-specific technology shocks in an RBC model. Here, our focus is not on the effects of this shock per se, but rather on the implications of sectoral heterogeneity for the effects of this shock on the aggregate variables of the model.
} 


\section{Figure 4: Responses of Models I through IV to a Sectoral Technology Shock}

White bars: Baseline Model I, Light Gray bars: Multi-Sector Model II (no utilization), Dark Gray bars: One-Sector Model III (capital utilization), Black bars: Multi-Sector Model IV (capital utilization wedge)
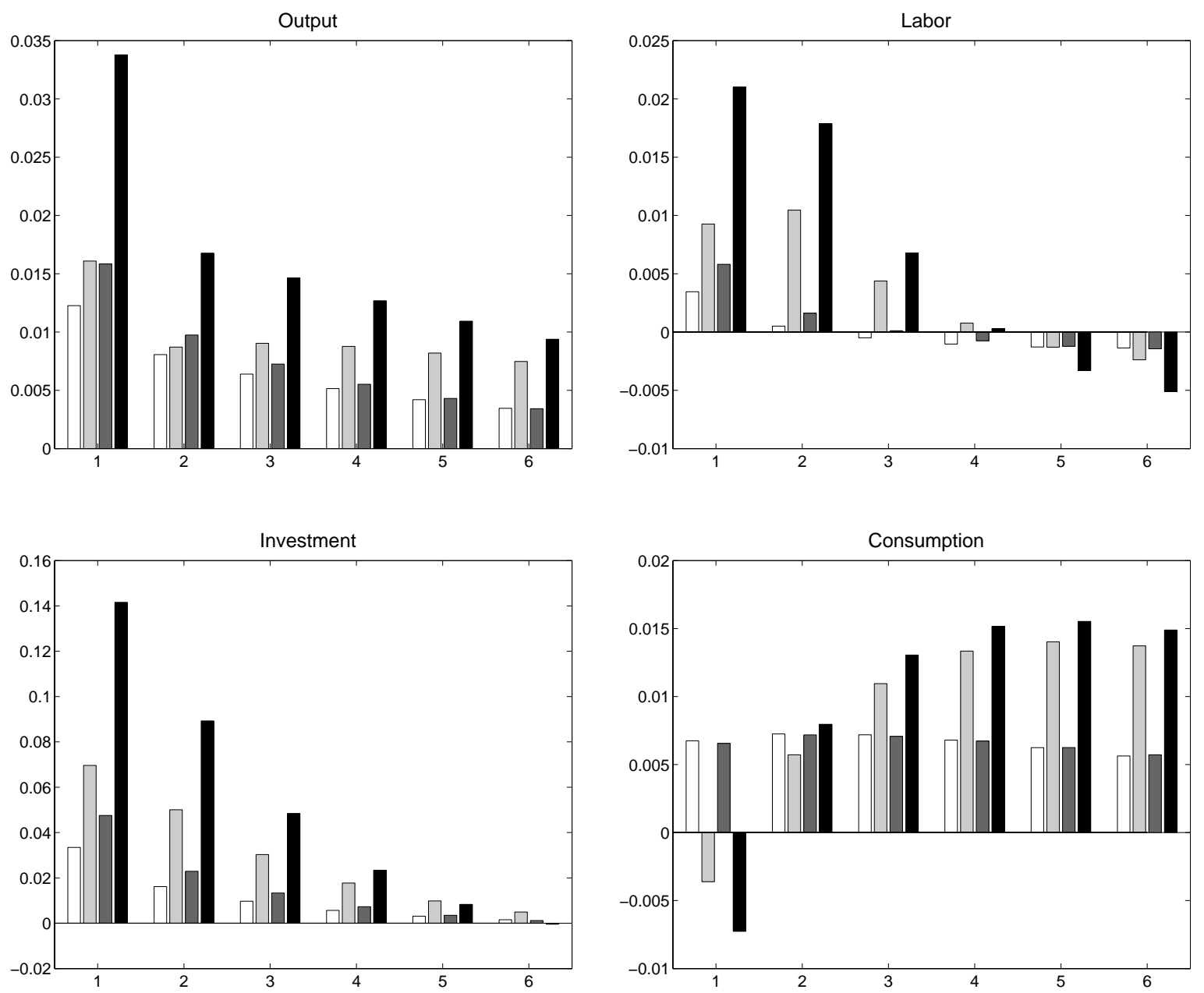

Sectoral Parameters (Models II \& IV)

$\begin{array}{rlrl}\alpha_{i} & =[.65, .65, .65] & C_{i} / C & =[1,0,0] \\ \omega_{i} & =[.25,1,1] & I_{i} / I & =[0,1,0] \\ \phi_{i} & =[1.6,1.6,1.6] & G_{i} / G & =[0,0,1] \\ \hat{A}_{i} & =[0, .0395,0]\end{array}$


models (I and III) are as defined previously (see Figure 1), with the addition of $\omega_{1}=1$ and $\phi_{1}=1.6$ in Model III. The parameters for the multi-sector models (II and IV) are given at the bottom of Figure 4. Note that it is assumed the sectors producing investment and government purchases derive full benefits from capital utilization $\left(\omega_{2}=1, \omega_{3}=1\right)$, while the consumption-good-producing sector has much lower returns $\left(\omega_{1}=.25\right)$, as motivated above. $^{29}$

The effects on Baseline Model I are exactly the same as in Figure 1, and are standard. The response of Model III looks very similar, though with some amplification due to the utilization margin, as found by Burnside and Eichenbaum (1996). The amplification provided by Model IV, however, is dramatically larger - the effects of the shock on output, labor, and investment are greater by roughly a factor of three. One reason for this dramatic amplification is the fall in the relative price of investment in the multi-sector Models (II and IV), which encourages agents to work harder and save more than in the one-sector models - i.e., the relative price channel. However, this is clearly not the only amplifying mechanism, since the responss in Model II are not nearly as great as in Model IV. The relative productivity channel is the primary reason for this difference: reallocation of production from a sector with low returns to utilization to one with high returns yields an increase in aggregate output and productivity of $0.35 \%$ (not shown) arising solely from the change in the distribution of inputs. This endogenous response of aggregate productivity is every bit as effective as an exogenous $35 \%$ increase in the size of the shock, as far as the agents are concerned, and they react accordingly. ${ }^{30}$

\section{Conclusions}

Sectoral heterogeneity, in and of itself, has first-order implications for the transmission of aggregate shocks to aggregate variables. We decompose these effects into two channels, a "relative price" channel and a "relative productivity" channel. These channels lie on top of the standard effects an aggregate shock would have in a one-sector DSGE setting.

\footnotetext{
${ }^{29}$ Results are essentially the same for a wide range of values of $\omega_{3}$, but it is crucial that $\omega_{2} \gg \omega_{1}$ in order to generate the additional amplification in Model IV that can be seen in Figure 4.

${ }^{30}$ The remainder of the difference in Model IV is explained partly by the increase in overall utilizaiton and partly by the fact that the relative price channel is larger in Model IV, because it allows production to more easily accommodate agents' shifts in demand without driving prices back toward their steady-state levels. This helps explain why the effects in Model IV are even greater than $135 \%$ those of Model II.
} 
The relative price channel results from changes in the relative prices of aggregate variables such as consumption, investment, and government purchases in response to a shock. These relative price changes in turn lead agents to alter their consumption and investment decisions and affect the equilibrium of all aggregate variabls in the model.

The relative productivity channel results from changes in the distribution of inputs across sectors of the economy. In particular, shifting an input from a sector with a relatively low marginal product to a sector with a higher marginal product leads to an increase in aggregate output and aggregate productivity. This in turn leads agents to respond with increased consumption, labor, and investment, just as they would to an exogenous increase in productivity. This channel has only second-order effects when firms are able to equalize the marginal product of the input across sectors in steady state. However, for inputs that are nontradeable, such as capital utilization, the effects are first-order. A reallocation of production from a sector with low returns to utilizing capital to one with high returns leads to first-order increases in aggregate output relative to aggregate inputs, even after taking changes in aggregate utilization into account.

In a variety of simulations, these two channels have effects that are quantitatively significant, in some cases even exceeding the direct effects of the driving shock itself. In addition, for reasonable parameterizations, the relative productivity channel generates procyclical aggregate productivity even when the driving shock is completely nontechnological in nature (such as a change in government purchases).

Finally, the very close correspondence of the basic multi-sector model (Model II) to traditional one-sector DSGE models - without the extraneous bells and whistles of previous papers on sectoral heterogeneity - allows for very clean comparison of the results to others in the literature and for easy extensibility of the model to incorporate additional features (consider, for example, the relative ease with which capital utilization was incorporated into the basic framework). In particular, extensions of the model to include job matching (Merz, 1999, Andolfatto, 1996) or external demand from a foreign sector would be very tractable and perhaps very rewarding. 


\section{Appendix A: Numerical Solution Procedure}

The numerical solution method for the models and their dynamic impulse responses is a generalization of the log-linearization procedure of King, Plosser, and Rebelo (1987, 1988). As discussed in the text, a complete log-linearization of the model is suspect when applied to equations at the sectoral level, because the relative importance of shocks at the is plausibly an order of magnitude larger than at the aggregate level-10 or even $20 \%$ as compared to 1 or $2 \%$. Only when these shocks have had a chance to die down is a linearization appropriate. Given the structure of adjustment costs or adjustment lags in the model and a candidate shock, it is typically possible to determine a set number of periods $k$ after which a linearization procedure is likely to produce a good approximation to the equations of the model. The system's equations for periods $t+k$ and beyond can then be linearized exactly as in the King, Plosser, and Rebelo framework. For example, taking $k=1$, we would guess hypothetical values for all the time $t$ variables of the system, require that they satisfy all the time $t$ constraints of the model nonlinearly, trace out the implied values of time $t+1$ state variables that result, and then solve the model linearly from period $t+1$ forward, given these "initial" time $t+1$ state variables. The accuracy of the initial guess is determined by the optimality conditions for the costate variables that must be satisfied on the boundary between periods $t$ and $t+1$; if these conditions are not satisfied, another guess is made and the solution procedure iterated until an equilibrium is found. Solving the model for $k=2$ is then simply a matter of adding another period's worth of guessed variables and another period's worth of costate restrictions, and so on for $k \geq 3$.

In the standard DSGE models considered in this paper, the assumption that capital is freely mobile one period after the realization of the shock allows us to set $k=1$. This is because even large movements in sectoral output, utilization, employment, and prices resulting from the shortrun fixity of capital will be largely eliminated by the beginning of period $t+1$, when capital can be freely reallocated across sectors. Longer lags to capital adjustment could easily be incorporated by extending this boundary forward a few periods, but wouldn't materially alter the solution algorithm or impact the demonstrated importance of effects of sectoral reallocation in the models.

Thus, the solution algorithm for the simulations in the text proceeds as follows: hypothesize values for the wage $w_{t}$ and relative prices $p_{i t}$ for period $t$. Given these quantities, all other time $t$ variables of the system can be determined. This then implies a value for the time $(t+1)$ capital stock $K_{t+1}$. The time $(t+1)$ distribution of capital across sectors is easily determined by a zeroprofit condition, since capital is freely mobile at the end of period $t$. Given $K_{t+1}$, the log-linear approximate solution for all time $(t+1)$ (and beyond) variables can quickly be obtained using the KPR linearization procedure. If the time $(t+1)$ and time $t$ values for consumption and labor satisfy the consumer's Euler equation, then we have an equilibrium; otherwise, we guess new values for $w_{t}$ and $p_{i t}$, and reiterate the procedure.

For this algorithm, convergence of the nonlinear routines was never a problem, and solutions were typically found very quickly, within a few iterations, even for models with a large number of sectors. Matlab routines that implement the algorithm are available from the author upon request.

Importance of the Nonlinear Solution Procedure. To investigate the quantitative importance of the nonlinear solution procedure described above relative to complete log-linearization of the model, Figure A1 repeats the simulation of Figure 4 using a completely log-linearized version of Models I-IV.

Comparing Figure A1 to Figure 4, which are identical except for the linearity or nonlinearity of the solution algorithm, we can see almost no difference between the two figures for the onesector models (I and III). However, the differences for the multi-sector models (II and IV) between Figure A1 and Figure 4 are quantitatively quite substantial. For example, the linearized solution 
Figure A1: Responses of Models I through IV to a Sectoral Technology Shock LOG-LINEARIZED SOLUTION

White bars: Baseline Model I, Light Gray bars: Multi-Sector Model II (no utilization), Dark Gray bars: One-Sector Model III (capital utilization), Black bars: Multi-Sector Model IV (capital utilization wedge)
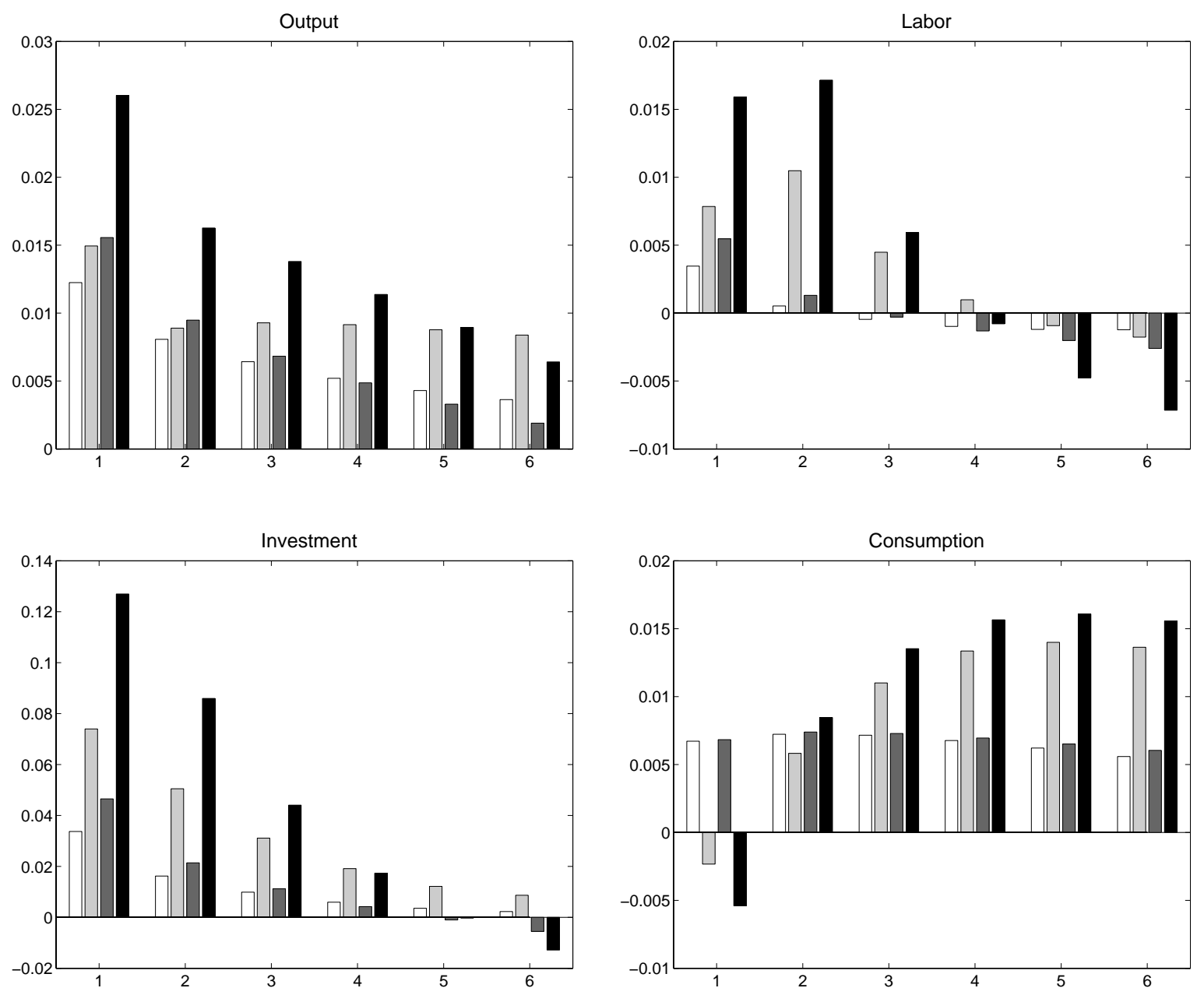

Sectoral Parameters (Models II \& IV)

$\begin{array}{rlrl}\alpha_{i} & =[.65, .65, .65] & C_{i} / C & =[1,0,0] \\ \omega_{i} & =[.25,1,1] & I_{i} / I & =[0,1,0] \\ \phi_{i} & =[1.6,1.6,1.6] & G_{i} / G & =[0,0,1] \\ \hat{A}_{i} & =[0, .0395,0]\end{array}$


procedure understates the first-period effect on aggregate output for Model IV (the black bars) by about one-third, and understates the effect on first-period aggregate labor by more than onefourth. These are big numerical errors, which arise because sectoral output changes are typically much larger in percentage terms than are the typical aggregate variable responses to a shock in standard one-sector models.

It is true that the basic qualitative findings of this paper are probably not highly sensitive to the use of a log-linearized as opposed to the more fully nonlinear solution procedure described above. Nevertheless, the linearized solution procedure can perform quite badly from a quantitative point of view in the sectoral models. As a result, if we had only used a log-linearized solution procedure, a reader could reasonably have questioned whether the results in the simulations were not in fact driven only by numerical approximation error in the computation of the solution to the multi-sector models. The use of the nonlinear solution procedure above essentially eliminates any concerns of this type. 


\section{Appendix B: Proofs of Propositions}

Proposition 1. Consider an economy described by Model II with $n>1$ sectors. An exogenous change in sectoral government purchases $G_{j t}$ or sectoral technology $A_{j t}$ in sector $j$ has a firstorder effect on relative prices $p_{i t}$ in general. Moreover, if there exists some $(i, j)$ such that $\eta_{i} \neq \eta_{j}$, $\xi_{i} \neq \xi_{j}, \gamma_{i} \neq \gamma_{j}$, or $\frac{\left(\partial F_{i} / \partial(A L)\right)^{2}}{\partial^{2} F_{i} / \partial(A L)^{2}} \neq \frac{\left(\partial F_{j} / \partial(A L)\right)^{2}}{\partial^{2} F_{j} / \partial(A L)^{2}}$, then a uniform exogenous change in government purchases $G_{i t}$ or a uniform change in technology $A_{i t}$ across all sectors $i$ has a first-order effect on relative prices $p_{i t}$ in general.

Proof: Let a circumflex over a variable denote the log-deviation of that variable from its baseline value (where baseline is the value assuming no shocks in period $t, \hat{G}_{i t}=0=\hat{A}_{i t}$ for all $i$ ) and let variables without time subscripts denote baseline values. Then, implicitly differentiating the equilibrium condition $A_{i t} \partial F_{i} / \partial(A L)=w_{t} / p_{i t}$ in every sector $i$, we have the first-order condition:

$$
\hat{A}_{i t}+\frac{p_{i} L_{i}}{w} \frac{\partial^{2} F_{i}}{\partial(A L)^{2}}\left(\hat{A}_{i t}+\hat{L}_{i t}\right)=\hat{w}_{t}-\hat{p}_{i t}
$$

using the fact that the capital stock $K_{i t}$ is fixed in period $t$. Letting $\alpha_{i}$ denote labor's share $w L_{i} / p_{i} Y_{i}$ in sector $i$, we have from the left-hand side of (II-5) the first-order condition $\hat{Y}_{i t}=$ $\alpha_{i}\left(\hat{A}_{i t}+\hat{L}_{i t}\right)$, and hence:

$$
\hat{Y}_{i t}=\frac{\alpha_{i} w}{p_{i} L_{i}} \frac{1}{\left|\partial^{2} F_{i} / \partial(A L)^{2}\right|}\left(\hat{A}_{i t}-\hat{w}_{t}+\hat{p}_{i t}\right),
$$

using $\partial^{2} F_{i} / \partial(A L)^{2}<0$. From the right-hand side of (II-5), we have:

$$
\hat{Y}_{i t}=\frac{C_{i}}{Y_{i}}\left[\hat{C}_{t}-\theta\left(\hat{p}_{i t}-\hat{P}_{C t}\right)\right]+\frac{I_{i}}{Y_{i}} \hat{I}_{t}+\frac{G_{i}}{Y_{i}} \hat{G}_{i t}
$$

Now, suppose that relative prices $\hat{p}_{i t}=0, i=1, \ldots, n$. Then for every sector $i$, we must have:

$$
\frac{\alpha_{i} w}{p_{i} L_{i}} \frac{1}{\left|\partial^{2} F_{i} / \partial(A L)^{2}\right|}\left(\hat{A}_{i t}-\hat{w}_{t}\right)=\frac{C_{i}}{Y_{i}} \hat{C}_{t}+\frac{I_{i}}{Y_{i}} \hat{I}_{t}+\frac{G_{i}}{Y_{i}} \hat{G}_{i t}
$$

We will show that this implies a contradiction - that, in order for supply and demand to be in equilibrium in all sectors after the given shock, some relative prices must adjust.

To do this, we reduce equation (B4) to a set of equations in $\hat{L}_{t}$ and exogenous variables by making use of the following relations:

$$
\begin{aligned}
\hat{I}_{t} & =\frac{Y}{I} \hat{Y}_{t}-\frac{C}{I} \hat{C}_{t}-\frac{G}{I} \hat{G}_{t} \\
\hat{Y}_{t} & =\sum \frac{\alpha_{i} p_{i} Y_{i}}{Y}\left(\hat{A}_{i t}+\hat{L}_{i t}\right)=\alpha\left(\hat{A}_{t}+\hat{L}_{t}\right) \\
\hat{C}_{t} & =\hat{w}_{t}-L\left[\frac{v^{\prime}}{v}-\frac{v^{\prime \prime}}{v^{\prime}}\right] \hat{L}_{t}
\end{aligned}
$$

where (B5) follows from the definition of $I_{t}$, (B6) from the production functions $F_{i}$, letting $\alpha \equiv$ $w L / Y$ and $\hat{A}_{t} \equiv \sum\left(L_{i} / L\right) \hat{A}_{i t}$, and (B7) from the equilibrium condition that the marginal rate of 
substitution equal the real wage. To express $\hat{w}_{t}$ in terms of aggregate $\hat{L}_{t}$ and exogenous variables, we sum over (B1), yielding:

$$
\sum \frac{\partial F_{i} / \partial(A L)}{\left|\partial^{2} F_{i} / \partial(A L)^{2}\right|} \hat{w}_{t}=\sum \frac{\partial F_{i} / \partial(A L)}{\left|\partial^{2} F_{i} / \partial(A L)^{2}\right|} \hat{A}_{i t}-L\left(\hat{A}_{t}+\hat{L}_{t}\right)
$$

Substituting (B5)-(B8) into (B4) yields:

$$
k_{1 i} \hat{L}_{t}=k_{2 i} \hat{A}_{i t}+k_{3 i} \hat{A}_{t}+k_{4 i} \sum \frac{\partial F_{h} / \partial(A L)}{\left|\partial^{2} F_{h} / \partial(A L)^{2}\right|} \hat{A}_{h t}+k_{5 i} \hat{G}_{i t}+k_{6 i} \hat{G}_{t}
$$

where each of the coefficients $k$ is a function of the parameters of the model (reported below). (B9) is a system of $n>1$ equations in one endogenous variable, $\hat{L}_{t}$, which cannot be solved for arbitrary values of the exogenous shocks $\hat{A}_{i t}$ and $\hat{G}_{i t}$, a contradiction. It follows that $\hat{p}_{i t} \neq 0$ in at least two sectors $i$ (the fact that $P_{t}=1$ implies that $\hat{p}_{i t}$ cannot change in only one sector.) Thus, relative prices must adjust in response to exogenous shocks in general, and this response is first-order.

Now consider the case of a uniform, exogenous shock $\hat{G}_{t}$ to government purchases in all sectors. Then $\hat{A}_{i t}=0$ for all $i, \hat{A}_{t}=0$, and $\hat{G}_{i t}=\hat{G}_{t}$. It follows that:

$$
k_{1 i} \hat{L}_{t}=\left(k_{5 i}+k_{6 i}\right) \hat{G}_{t}
$$

for all $i$. Then (B10) is a system of $n>1$ equations in one endogenous variable, $\hat{L}_{t}$, which has no solution unless $\left(k_{1 i}, k_{5 i}+k_{6 i}\right)$ is the same across all sectors $i$, up to a constant multiple. Since this is ruled out by assumption, we must have that relative prices adjust. An analogous argument applies to a technology shock $\hat{A}_{t}$ that is uniform across sectors.

The values of the coefficients $k$ in (B9) are as follows:

$$
\begin{aligned}
k_{1 i} & =-k_{3 i}+\left(\left(\eta_{i} / p_{i}\right)^{\theta}-\xi_{i}\right) C L\left[\frac{v^{\prime}}{v}+\frac{\left|v^{\prime \prime}\right|}{v^{\prime}}\right] \\
k_{2 i} & =-\frac{\left(\partial F_{i} / \partial(A L)\right)^{2}}{\left|\partial^{2} F_{i} / \partial(A L)^{2}\right|} \\
k_{3 i} & =\alpha \xi_{i} Y-k_{4 i} L \\
k_{4 i} & =\left[-k_{2 i}+\left(\left(\eta_{i} / p_{i}\right)^{\theta}-\xi_{i}\right) C\right]\left(\sum \frac{\partial F_{h} / \partial(A L)}{\left|\partial^{2} F_{h} / \partial(A L)^{2}\right|}\right)^{-1} \\
k_{5 i} & =\gamma_{i} G \\
k_{6 i} & =-\xi_{i} G
\end{aligned}
$$


Proposition 2. Consider an economy described by Model II with $n>1$ sectors.

(i) Suppose that the equilibrium value of $P_{K t}, P_{C t}$, or $P_{G t}$ changes. Then, in general, the equilibrium values of $C_{t}, I_{t}, L_{t}$, and $Y_{t}$ must also change. Moreover, this relationship is first-order.

(ii) Suppose that the equilibrium value of $p_{i t}$ changes for some sector $i$. If the coefficients $\xi_{j}, \eta_{j}$, or $\gamma_{j}, j=1, \ldots, n$, are such that any of $P_{K t}, P_{C t}$, or $P_{G t}$ change as a result, then the equilibrium values of $C_{t}, I_{t}, L_{t}$, and $Y_{t}$ must also change by part (i). Alternatively, if $\eta_{i}>0$ and $\eta_{j}>0$ for some $j \neq i$, then the equilibrium values of $C_{t}, I_{t}, L_{t}$, and $Y_{t}$ must also change, and this relationship is first-order.

Proof: Given a change in the equilibrium values of $P_{K t}, P_{C t}$, or $P_{G t}$, suppose that the equilibrium values of $C_{t}, I_{t}$, and $Y_{t}$ are unchanged. Then, equilibrium condition (II-2) implies that $K_{t+1}$ must be different. By Bellman's principle and the fact that the optimal $C_{t}$ is a function of the state $K_{t}$, then the equilibrium value of $C_{t+1}$ is different. But this would violate the Euler condition for intertemporal optimality, a contradiction.

It follows that the equilibrium value of at least one of $C_{t}, I_{t}$, and $Y_{t}$ must be different. But then it follows from the intratemporal equilibrium conditions (that $Y=C+I+G$ and that the marginal rate of substitution equals the real wage) that each of $C_{t}, I_{t}, L_{t}$ and $Y_{t}$ must be different in general as well. The proof of (i) is completed by noting that all of the above relationships are first-order.

Turning to (ii), suppose that all of $P_{K t}, P_{C t}$, and $P_{G t}$ are unchanged (because there are offsetting changes in prices $p_{j t}, j \neq i$ ) and all of $C_{t}, I_{t}, L_{t}$, and $Y_{t}$ are unchanged. If $\eta_{i}>0$ and if more than one good enters into the consumption bundle (i.e., $\eta_{j}>0$ for some $j \neq i$ ), then $p_{i t} / P_{C t}$ and the right-hand side of (II-5) must change in general. In particular, if $p_{i t} / P_{C t}$ increases, then $C_{i t}$ and the right-hand side of (II-5) - the demand for good $i$ - must fall.

Consider now the left-hand side of (II-5) - the supply of good $i$. We have $\partial F_{i} / \partial L_{i}=w_{t} / p_{i t}$, $\partial F_{i} / \partial L_{i}>0$, and $\partial^{2} F_{i} /\left(\partial L_{i}\right)^{2}<0$. If $C_{t}$ and $L_{t}$ are unchanged, as hypothesized, then $w_{t}$ must also be unchanged. Thus, if $p_{i t}$ increases, we must have that $w_{t} / p_{i t}$ falls and hence $L_{i t}$ rises. This implies that the left-hand side of (II-5) - the supply of good $i$-must rise. Note that this contradicts the assumptions of the previous paragraph. Thus, it must be true that one or more of $C_{t}, I_{t}, L_{t}$ and $Y_{t}$ are changed. Then, as in part (i), each of $C_{t}, I_{t}, L_{t}$, and $Y_{t}$ must be different in general as well. 


\section{References}

Abraham, Katherine and Lawrence Katz. "Cyclical Unemployment: Sectoral Shifts or Aggregate Disturbances?" Journal of Political Economy 94 (1986), 507-22.

Andolfatto, David. "Business Cycles and Labor Market Search," American Economic Review 86 (1996), 112-32.

Arrow, Kenneth and F.H. Hahn. General Competitive Analysis (San Francisco: Holden-Day, 1971).

Baily, Martin, Charles Hulten, and David Campbell, "Productivity Dynamics in Manufacturing Plants," Brookings Papers on Economic Activity (1992), 187-249

Basu, Susanto. "Procyclical Productivity: Increasing Returns or Cyclical Utilization?" Quarterly Journal of Economics 109 (1996), 719-51.

Basu, Susanto and John Fernald. "Returns to Scale in U.S. Production: Estimates and Implications," Journal of Political Economy 105 (1997), 249-83.

Basu, Susanto and John Fernald. "Aggregate Technology and Aggregate Productivity," European Economic Review 46 (2002), 963-91

Burnside, Craig and Martin Eichenbaum. "Factor-Hoarding and the Propagation of Business Cycle Shocks," American Economic Review 86 (1996), 1154-74.

Burnside, Craig, Martin Eichenbaum, and Sergio Rebelo. "Capital Utilizaton and Returns to Scale," NBER Macroeconomics Annual (1995), 67-110.

Burnside, Craig, Martin Eichenbaum, and Sergio Rebelo. "Sectoral Solow Residuals," European Economic Review 40 (1996), 861-9.

Christiano, Lawrence and Martin Eichenbaum. "Current Real-Business-Cycle Theories and Aggregate Labor-Market Fluctuations," American Economic Review 82 (1992), 430-50.

Davis, Steven. "Fluctuations in the Pace of Labor Reallocation," Carnegie-Rochester Conference Series on Public Policy 21 (1987), 335-402.

Diewert, W.E. "Fisher Ideal Output, Input, and Productivity Indexes Revisited," in Diewert, W.E. and A.O. Nakamura (eds.), Essays in Index Number Theory (Elsevier: New York, 1993), 318-57.

Dupor, BiLl. "Aggregation and Irrelevance in Multi-Sector Models," Journal of Monetary Economics 43 (1999), 391-410.

Greenwood, Jeremy, Zvi Hercowitz, and Gregory Huffman. "Investment, Capacity Utilization, and the Real Business Cycle," American Economic Review 78 (1988), 402-17.

Greenwood, Jeremy, Zvi Hercowitz, and Per Krussell. "The Role of Investment-Specific Technological Change in the Business Cycle," European Economic Review 44 (2000), 91-115.

Griliches, Zvi And V. Ringstad. Economies of Scale and the Form of the Production Function: An Econometric Study of Norwegian Manufacturing Establishment Data (North-Holland: Amsterdam, 1971).

Galí, Jordi. "Monopolistic Competition, Business Cycles, and the Composition of Aggregate Demand," J. Econ. Theory 63 (1994), pp. 73-96.

Hamilton, James. "A Neoclassical Model of Unemployment and the Business Cycle," Journal of Political Economy 96 (1988), 593-617.

Horvath, Michael. "Cyclicality and Sectoral Linkages: Aggregate Fluctuations from Independent Sectoral Shocks," Review of Economic Dynamics 1 (1998). 
Horvath, Michael. "Sectoral Shocks and Aggregate Fluctuations," Journal of Monetary Economics 45 (2000), 69-106.

King, Robert, Charles Plosser and Sergio Rebelo. "Production, Growth, and Business Cycles," J. Monetary Econ. 21 (1988), 195-232, and unpublished Technical Appendix, University of Rochester (1987).

LiLien, DAvid. "Sectoral Shifts and Cyclical Unemployment," Journal of Political Economy 90 (1982), 777-93.

Long, John And Charles Plosser. "Real Business Cycles," Journal of Political Economy 91 (1983), 39-69.

Lucas, Robert. "Capacity, Overtime, and Empirical Production Functions," American Economic Review 60 (1970), 23-7.

Merz, Monika. "Heterogeneous Job Matches and the Cyclical Behavior of Labor Turnover," Journal of Monetary Economics 17 (1999), 91-124.

Phelan, Christopher and Alberto Trejos. "The Aggregate Effects of Sectoral Reallocations," Journal of Monetary Economics 45 (2000), 249-68.

Ramey, Valerie and Matthew Shapiro. "Costly Capital Reallocation and the Effects of Government Spending," Carnegie-Rochester Conference Series on Public Policy 48 (1998), 14594.

Rogerson, Richard. "An Equilibrium Model of Sectoral Reallocation," Journal of Political Economy 95 (1987), 824-34.

Rotemberg, Julio and Michael Woodford. "Oligopolistic Pricing and the Effects of Aggregate Demand on Economic Activity," Journal of Political Economy 100 (1992), 1153-1207.

Rotemberg, Julio and Michael Woodford. "Dynamic General Equilibrium Models with Imperfectly Competitive Product Markets," in Frontiers of Business Cycle Research ed. Thomas Cooley (Princeton: Princeton Univ. Press, 1995).

Shapiro, Matthew. "Macroeconomic Implications of Variation in the Workweek of Capital," Brookings Papers on Economic Activity (1996), 79-133.

Summers, Lawrence. "Theory Ahead of Business Cycle Measurement: Comment," Federal Reserve Bank of Minneapolis Quarterly Review 10 (1986), 23-30. 